\title{
Exceptionally preserved cryptoniscium larvae - morphological details of rare isopod crustaceans from French Cretaceous Vendean amber
}

\author{
Mario Schädel, Vincent Perrichot, and Joachim T. Haug
}

\begin{abstract}
Epicaridea is an ingroup of Isopoda that comprises only parasitic crustaceans. Within parasitic isopods, epicarideans represent a special case: throughout their ontogeny they switch from a small intermediate host (copepod) to a final host (various larger crustaceans), and develop through distinct larval phases (epicaridium, microniscium and cryptoniscium). Young males of some species retain a larval morphology. Recent findings of fossil epicarideans in amber from the Miocene of Mexico consisted in the only epicaridean body fossils, until one specimen has been figured from Cretaceous amber from France. Here we provide a detailed analysis of this specimen and 20 more specimens from the same locality. The presented specimens represent the oldest occurrence of epicaridean body fossils, extending their fossil record by 67 million years.

The fossils are exceptionally well preserved and, despite their small size of less than $0.5 \mathrm{~mm}$, reveal even fine morphological details. The specimens correspond either to cryptoniscium larvae or males that have retained their larval morphology. There are no morphological features in the fossils that argue against conspecifity of all specimens. All character states found in the fossils are also present in extant species. Given the displayed combination of character states and the age difference, it is unlikely that the specimens are conspecific to any extant species nor to much younger fossils from the Miocene of Mexico. The species Vacuotheca dupeorum gen. et sp. nov. is described and interpreted as an epicaridean of uncertain affinities, but that is not part of the epicaridean ingroup Dajidae. Furthermore, multiple aspects of the evolutionary history of parasitic isopods and epicarideans in particular are discussed. This includes possible scenarios for host changes that could have led to the life cycle of modern epicarideans and the evolution of size within epicaridean larvae.
\end{abstract}

http://zoobank.org/30999446-D188-41C9-9643-98CC42CB7FDB

Schädel, Mario, Perrichot, Vincent, and Haug, Joachim T. 2019. Exceptionally preserved cryptoniscium larvae - morphological details of rare isopod crustaceans from French Cretaceous Vendean amber. Palaeontologia Electronica 22.3.71 1-46. https://doi.org/ $10.26879 / 977$

palaeo-electronica.org/content/2019/2757-cretaceous-epicaridea

Copyright: November 2019 Palaeontological Association.

This is an open access article distributed under the terms of Attribution-NonCommercial-ShareAlike 4.0 International (CC BY-NC-SA 4.0 ), which permits users to copy and redistribute the material in any medium or format, provided it is not used for commercial purposes and the original author and source are credited, with indications if any changes are made.

creativecommons.org/licenses/by-nc-sa/4.0/ 
Mario Schädel. Ludwig-Maximilians-Universität München, Department of Biology II, Zoomorphology group, Großhaderner Straße 2, 82152 Planegg-Martinsried, Germany. mario.schaedel@palaeo-evo-devo.info Vincent Perrichot. Univ. Rennes, CNRS, Géosciences Rennes, UMR 6118, 35000 Rennes, France. vincent.perrichot@univ-rennes1.fr Joachim T. Haug. Ludwig-Maximilians-Universität München, Department of Biology II, Zoomorphology group, Großhaderner Straße 2, 82152 Planegg-Martinsried, Germany and Ludwig-Maximilians-Universität München, GeoBio-Center, Richard-Wagner-Str. 10, 80333 München, Germany. joachim.haug@palaeoevo-devo.info

Keywords: aquatic amber; Cymothoida; Epicaridea; fluorescence microscopy; fossilised ontogeny; palaeoparasitism

Submission: 3 March 2019. Acceptance: 17 September 2019.

\section{INTRODUCTION}

\section{General Background}

Isopoda (woodlice and their relatives) is an enormously diverse group of malacostracan crustaceans. Having a marine origin, isopod species did not only master the transition to a fully terrestrial life (Oniscidea), they also inhabit deep sea and freshwater environments, and some groups even developed parasitic lifestyles (Williams and Bunkley-Williams, 2019). Some isopod species have been known as parasites of fishes and crustaceans for a long time (e.g., Müller, 1862). However, the evolution of these groups of parasites is still quite enigmatic to the present day.

Fossils can provide important clues to the early evolution of a group, by combining highly specialised modern-type features with more plesiomorphic aspects of the morphology. Fossils may provide evolutionary "steps-in between". Yet, in the case of parasitic isopods it is not so simple.

Isopod fossils are not very common in the fossil record in general and identifying a parasitic lifestyle based on fossil morphology is quite challenging (see discussion in Nagler and Haug, 2015). Thus, the record of parasitic isopod body fossil is, so far, highly limited.

Even when fossils are available, a solid understanding of the biology of the suspected extant relatives is required to interpret their significance. Also, hypotheses on the relationships between animal groups of interest should always be critically evaluated in light of the usually more detailed known extant species.

Whether all parasitic isopods belong to a monophyletic group that excludes non-parasitic species is still a matter of debate. It seems widely accepted that most fish parasites and some predatory and scavenging forms (Cirolanidae, Corallani- dae, Tridentella, Aegidae, and Cymothoidae) are closely related and form the monophyletic group Cymothoida (Wägele, 1989; Brusca and Wilson, 1991; Dreyer and Wägele, 2001; Brandt and Poore, 2003). However, the position of Gnathiidae (only larval forms are fish parasites) and Epicaridea (parasites on crustaceans) is still under debate (Wägele, 1989; Brusca and Wilson, 1991; Dreyer and Wägele, 2001, 2002). Brusca and Wilson (1991) suggested a sister group relationship between Epicaridea and Gnathiidae (outside of Cymothoida), whereas Dreyer and Wägele (2001, 2002) suggested Epicaridea being the sister group of Cymothoidae (within Cymothoida).

The analysis of Nagler et al. (2017) combines close relationships proposed for Cymothoidae and Epicaridea (Wägele, 1989) and between Gnathiidae and Epicaridea (Brusca and Wilson, 1991) by interpreting a group including Gnathiidae and Epicaridea as a sister group to Cymothoidae. Support for this view is currently mainly provided by an exceptionally preserved fossil of the group Urda Münster, 1840, combining characters of Epicaridea, Gnathiidae and Cymothoidae (Nagler et al., 2017).

Isopoda is an ingroup of the diverse group Peracarida. All peracaridans share a unique specialisation: the adult female develops a brood pouch that is covered with sclerites protruding from the legs (oostegites), providing for prolonged maternal care. As a result, most species do not produce true larval offspring in the strict sense (for difficulties of the term see Haug, in press). The immatures, that leave the brood pouch, largely resemble the adults in morphology and ecology (but see discussion in Lang et al., 2007). This holds also true for the stem species of Isopoda ( $A x$, 2000). 
In fish-parasitising isopods (mostly species of Aegidae and Cymothoidae) dispersal happens in the so-called manca stage or the subsequent juveniles. The manca stage lacks a fully developed seventh pereopod (thoracic appendage 8, appendage of post-ocular segment 13) that the adults have (Boyko and Wolff, 2014) but otherwise resembles the adult in the general body organisation. Yet, based on their ecological function (dispersal) they may be interpreted as functional larvae (if dispersal is considered a larval feature; see Haug, in press). In Cymothoidae subsequently gradual morphological changes in favour of a close parasite-host interaction can happen, which can, for example, lead to the loss of the bilateral symmetry in late stages of the individual development (e.g., van der Wal et al., 2019).

In epicarideans, much smaller offspring is released from the brood pouch and the ontogenesis can be separated in distinct steps with very different ecological functions corresponding to very different morphologies, too (Figure 1). In most epicarideans the ontogeny can be differentiated into three distinct true larval stages, accepted as such by most authors - epicaridium, microniscium and cryptoniscium - and the subsequent further development towards adults (Williams and Boyko, 2012; Boyko and Wolff, 2014).

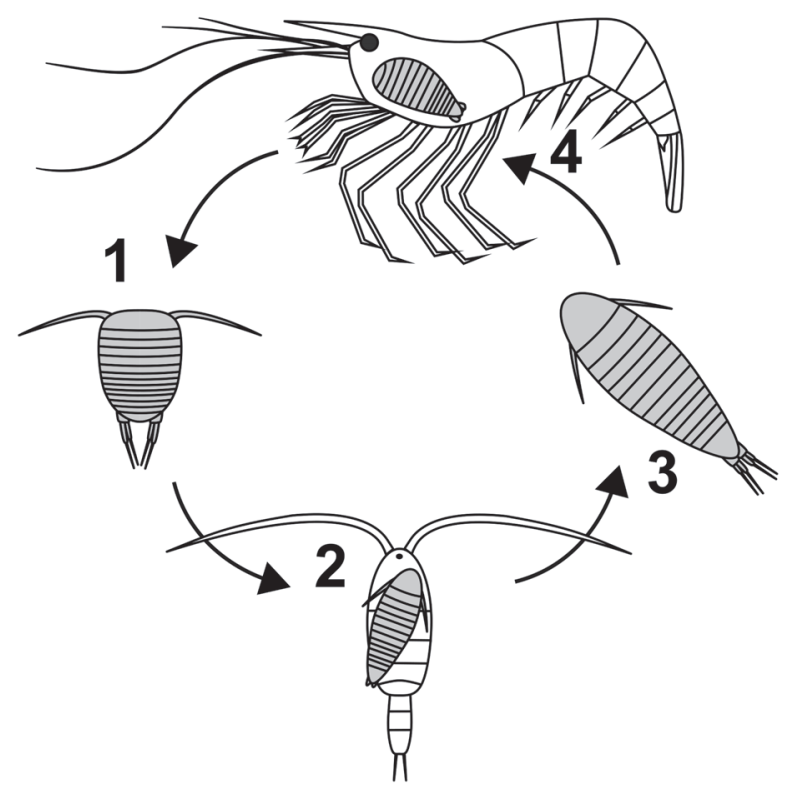

FIGURE 1. Sketched and simplified illustration of the life cycle of epicarideans. 1.1: Planktic epicaridium larva. 1.2: Microniscium larva feeding on a copepod (intermediate host). 1.3: Planktic cryptoniscium larva. 1.4: Adult feeding on a crustacean final host.

\section{The Post-embryonic Ontogeny of Epicarideans}

Epicaridium. With only one reported exception (Miyashita, 1940) epicaridean crustaceans hatch from their eggs as epicaridium larvae. The name of this larval type derives from its discovery on the definitive host, i.e., a caridean shrimp, where larvae were released from the brood pouch of the female (Fraisse, 1878). Epicaridium larvae are stout in appearance with short but wide thoracic segments. There is a clear distinction between the free trunk segments (segments that have a dorsal sclerite and not conjoined with others) into pereonsegments (posterior, free thoracic segments) and the pleon-segments regarding the morphology of the legs. At least the anterior pereopods are well differentiated. The pleopods bear distinct setae (Dale and Anderson, 1982).

After their release they become planktic and infest copepods (Boyko et al., 2013). The small epicaridium larvae grasp the appendages of the copepods and move to the trunk where they will moult and transform to the next distinct larval stage: the microniscium.

Microniscium. Relatively little is known about the life of microniscia, besides that they are parasitising copepods crustaceans. At some point (maybe still as epicaridia?) they pierce through the integument of the host and from then on feed on the host's body fluid (Pike pers. comm. in Marshall and Orr, 2013). Due to the relatively large size of the microniscium compared to its host it causes a tremendous negative effect on the reproductive rate of the copepods individual (Uye and Murase, 1997). It is also likely (but has not been reported yet) that the microniscium kills its host. In this case, the microniscium would rather correspond to a parasitoid than a parasite. The mechanism of detachment from this intermediate host and when or where moulting towards next stage happens remains to be investigated.

The epicarideans use the phase of attachment to the copepod with a steady income of nutrients to drastically change the overall body morphology. While the epicaridium is rather stout in appearance compared to the subsequent larval stages, it possesses well-developed setae and specialized, fully developed appendages (Anderson and Dale, 1981). The microniscium is more slender. Early microniscia lack fully developed thoracic appendages, and the seventh pereopod (last thoracic appendage) is missing entirely as well as the setation of the pleopods. The absence of the last thoracic appendage is reminiscent to the condition in manca stages in other isopod species. During the 
microniscium larval stage a significant growth and a morphological change (supposedly without moulting) towards the morphology of the cryptoniscium stage can be observed (Anderson and Dale, 1981).

Cryptoniscium. The cryptoniscium is the last distinct larval stage that can be observed throughout the ontogeny of species of all epicaridean lineages. The cryptoniscium develops from a microniscium that is attached to a planktic copepod. Cryptoniscia are all still rather small and resemble microniscia in overall body shape (Nielsen and Strömberg, 1973). Similar to epicaridia, cryptoniscium larvae are planktic and in search for a host. They swim actively and at least some cryptoniscia are able to curl up (for protection?) (Fraisse, 1878). The overall morphology of cryptoniscium larvae is relatively uniform in all epicaridean species known from this stage (Anderson and Dale, 1981). The body is elongated with a convex dorsal and a concave ventral surface. The mouthparts form a sucking mouth cone. The seventh pereopod (thoracic appendage eight) is present and the dactyli of the pereopods, i.e., the terminal elements of posterior seven thoracic appendages, are recurved forming a functional subchelae with the proximal appendage elements. The pleopods have long natatory setae; the uropods are rod-shaped with long distal setae.

For the species Entoniscoides okadai Miyashita, 1940, it has been reported that the hatching stage has a cryptoniscium-like habitus. This was shown by the examination of the brood pouch of an adult female where pre-hatched and hatched larvae, with the appearance of a cryptoniscium, were observed. Furthermore, an embryonic stage resembling microniscium larvae has been described (although this statement is not directly evident from the provided photograph; Miyashita, 1940). Without free swimming epicaridia, it is likely that Entoniscoides okadai is not parasitising copepods. With respect to the current phylogenetic hypothesis it seems unlikely that this represents an ancestral feature, but is better understood as a decrease of step numbers during ontogeny along with an intensification in maternal care.

Later development and sex. The stage following the cryptoniscium has been termed 'bopyridium' by some authors (e.g., Oliveira and Masunari, 2006). Boyko and Wolf (2014) critically questioned the value of this term. We support their critical view. The term indicates the presence of a distinct stage of life, yet it refers to a phase of morphological transition between the cryptoniscium and the adult (including several moults) and cannot be properly outlined using morphological features. In other groups comparable stages of eucrustaceans would have been simply addressed as 'juveniles'.

The sexual development is highly variable within epicaridean species. It can be (1) strictly protandric, meaning that all individuals are males at first, or (2) depend on an external trigger, such as the presence of on adult female on the same host. Yet, also a direct, externally triggered, development from the cryptoniscium towards both sexes is possible (summarised in Wägele, 1989). Possible genotypic determination for both sexes has also been reported once (Hiraiwa, 1936). When a female dies on the alive host, adult males can also transform into functional females (Reverberi, 1947).

Hosie (2008) stated that in the epicaridean subgroup Cryptoniscoidea males are often not distinguishable from cryptoniscia. The author uses the term 'male' for all non-planktic cryptoniscoideans that show no signs of modification towards a female habitus. We think this practice is critical; it heavily depends on assumptions about the sexual development and behaviour of epicarideans, which has not been studied in detail for most species.

\section{Epicaridean Ecology}

The entire larval phase of epicaridean crustaceans lasts around 10 to 30 days (Caroli, 1928; Anderson, 1975). The dispersal of the larval stages strongly correlates with the length of the larval phases. A passive transportation of up to $100 \mathrm{~km}$ distance has been reported during the time of the larval development (Owens and Rothlisberg, 1991). Further spatial dispersal obviously depends on the mobility of the host.

As their name suggests, adult epicarideans can be found especially on caridean shrimps. However, they are not restricted to them as final hosts, but also infest a variety of other crustaceans including other isopod species (Nielsen and Strömberg, 1965). Some species are also hyperparasitic on other epicarideans (Rybakov, 1990) or rhizocephalans (parasitic barnacles) (Williams and Boyko, 2012). Epicarideans have even be reported infesting cephalopods (Pascual et al., 2002); the authors suggest that similar cases may have simply been overseen in the past due to their small size. Hence, cephalopods could indeed represent additional host species.

Given the planktic dispersal stages in Epicaridea and the multiplicity of hosts observable in only one species (Bourdon, 1968), it is surprising to note the apparent impacts of geographical bounda- 
ries on the distribution of extant representatives. Markham (1968) mentioned the example of the epicaridean ingroup Orbioninae (Bopyroidea), which occurrence is restricted to the Indo-Pacific although suitable hosts are globally distributed.

Epicarideans are not limited to full marine environments but also occur in brackish estuarine habitats (Anderson and Dale, 1981). There are also records for species living in strict freshwater environments (Chopra, 1923).

\section{Epicaridean Ingroup Relationships}

As a result of their complex life cycle in combination with the presence of two planktic larval stages, associating larvae and adults is challenging. Thus, many species are known either as cryptoniscium larvae only (e.g., Schultz, 1975) or lack the description of this stage (e.g., Williams and An, 2009). This clearly affects the research on the systematics of the group, leading Boyko et al. (2013, p. 496) to the following assertion about the taxonomy within Epicaridea: "[...] genera are defined by the gross morphology of the females, and species by characters of cryptoniscium larvae." Future studies have to overcome the taxonomic bias that has been caused by the arbitrary distinctions between species and higher level characters.

Very few studies have focused on the epicaridean ingroup relationships. Beside a few older publications (Shino, 1965; Markham, 1968; reviewed in Boyko and Williams, 2009) for which the results are non-replicable (lacking any description of methods), there are only three studies focusing on this issue (Wägele, 1989; Boyko et al., 2013; Boyko and Williams, 2015). These phylogenetic analyses are both limited with respect to the number of included epicaridean species and, as a consequence, are complementary rather than comparable (see Figure 2). Both found Entoniscidae as the sister group of Bopyridae and Dajidae inside Cryptoniscoidea.

\section{Fossil Record of Epicaridea}

Until recently, there was simply no report for epicaridean body fossils. Hitherto, the fossil record of Epicaridea was consisting of swellings observed from the branchial chambers of fossil decapod crustaceans. These swellings were first identified

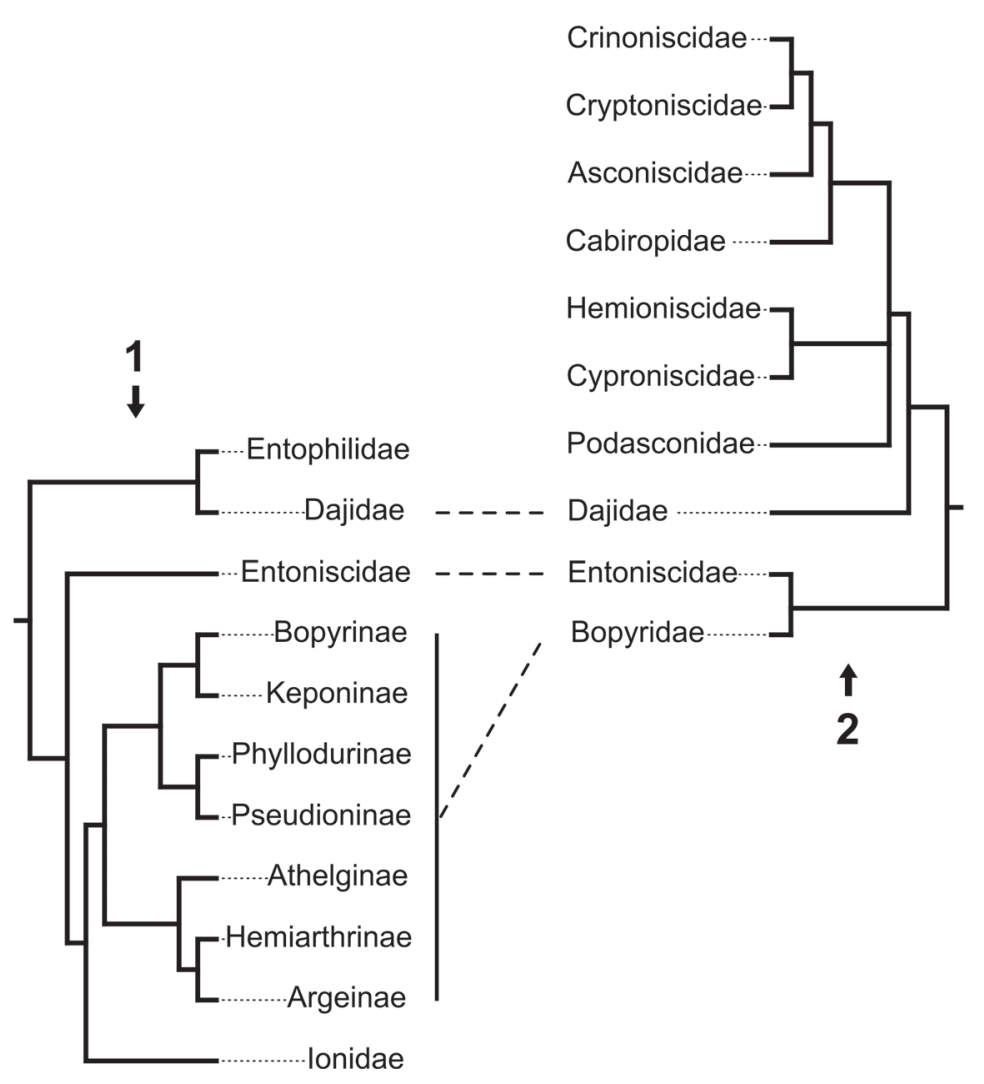

FIGURE 2. Confronting phylogenetic hypotheses in Epicaridea. Dashed lines represent supported monophyletic groups. 2.1: Molecular phylogeny from Boyko et al. (2013). 2.2: Phylogeny based on putative apomorphic morphological characters from Wägele (1989). 
by Bell (1863) and attributed by actualism to the internal colonization of the gill chamber, as nowadays performed by adult bopyroideans.

These fossil deformations supposedly induced by epicarideans have been listed and reviewed by Markham (1968), Wienberg Rasmussen et al. (2008), Klompmaker et al. (2014) and Klompmaker and Boxhall (2015). Their oldest occurrence is reported from a lobster-like crustacean (Erymidae) from the Toarcian (Lower Jurassic) of Western New Guinea (Soergel, 1913). This occurrence is questionable, as the repository of the depicted specimen is unknown, and because there is no record for such swellings in the Middle Jurassic so far (see also Klompmaker et al., 2014; Klompmaker and Boxshall, 2015). Klompmaker et al. (2014) reported a 'peak' in infestation during the Late Jurassic and supposed that this, rather than being a sampling artefact, could be linked to synecological reasons (occurrence of potential host species, biological defence strategies, etc.). Klompmaker et al. (2014) furthermore showed that more different species of true crabs (Brachyura) were infected in comparison to the representatives of its sister group (squat lobster, hermit crabs, false crabs; all together Anomura/Anomala). Yet, anomuran/anomalan crustaceans seem to have been more frequently infected than brachyuran crabs when considering the number of infected individuals per taxon for a Cretaceous assemblage.

Klompmaker et al. (2014) also erected the ichnotaxon Kanthyloma crusta for these Epicarideacaused swellings (see Klompmaker and Boxhall, 2015 for a further discussion regarding this nomenclatural practice). Attempts have been made to investigate the preservation of isopod body fossils within swellings in fossil crustaceans through computed tomography without success (N. Robin, 2019 pers. comm.). In experimental studies on the taphonomy of decapod crustaceans, remains of epicarideans are still present up to 25 days after the death of the infected host (Klompmaker et al., 2017).

A preservation type that could have the chance to preserve epicarideans is amber. That living arthropods submerged in water can get trapped by resin was experimentally shown (Schmidt and Dilcher, 2007) and can be explained by active or passive collision with the submerged resin (Figure 3 ). Yet, aquatic and especially marine organisms are relatively rare in amber considering their overall proportion in amber inclusions. However, there are some aquatic or even marine organisms in many amber localities (Schmidt et al., 2004; Key-

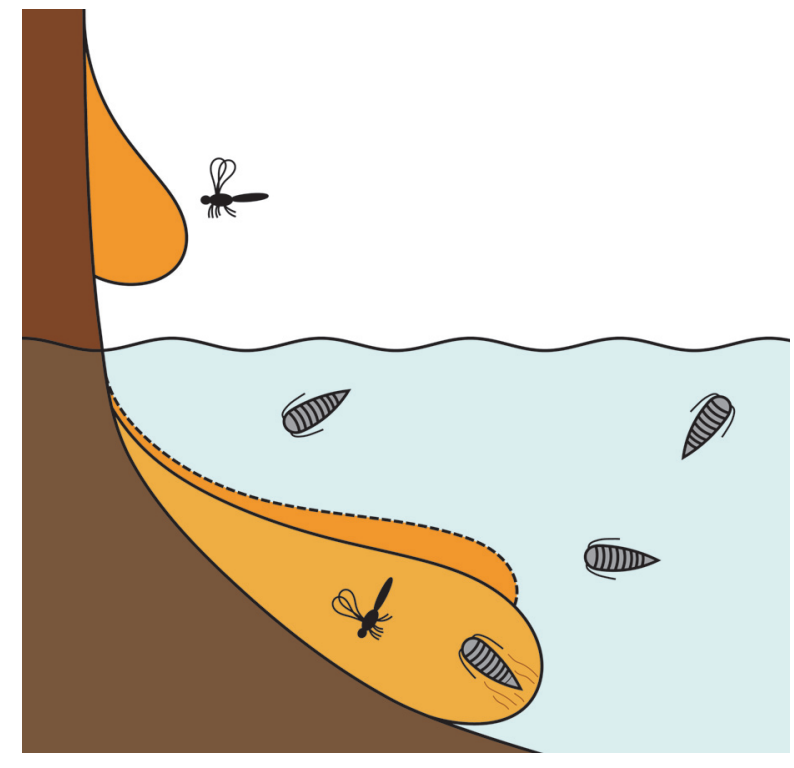

FIGURE 3. Illustration of possible entombment conditions suggested for Vendean amber: cryptoniscium larvae living in an aquatic environment close to the resin producing tree and getting trapped by making contact with submerged liquid resin.

ser and Weitschat, 2005; Girard et al., 2008; Saint Martin et al., 2015; Serrano-Sánchez et al., 2015, 2016; Xing et al., 2018).

More recently there were two reports of epicaridean body fossils preserved in amber. 1) There is a record from Miocene Mexican amber (SerranoSánchez et al., 2016). The fossils, which come from the Campo La Granja site, are clearly recognisable as larval epicarideans. These specimens were the first fossil record of epicaridean body fossils as well as a rare occurrence of fossil crustacean larvae in general. 2) Shortly after this primary description, Néraudeau et al. (2017) reported a second set of epicaridean larvae in the palaeontological content of a new French amber deposit. In this case, the fauna is significantly older than the Mexican epicarideans (about 90 million years) and allows access to better apparent morphological details.

Here, we describe 21 exceptionally well-preserved epicarideans from Cretaceous amber of Vendée, France. We further discuss the implications of the find for our understanding of the evolutionary history of epicaridean crustaceans. The aspect of body size for the known fossil epicaridean larvae in comparison to the extant representatives is discussed. Also, we critically discuss multiple possible scenarios that could have lead to the complex life cycle of extant epicarideans. The taphonomical implications of the herein presented fossils are discussed with respect to the circum- 
stances that could have lead to their preservation in amber.

\section{GEOLOGICAL SETTING}

The Vendean amber deposit is located in northwestern France (Pays-de-la-Loire region) at La Robinière, a locality near the village of La Garnache (department of Vendée). The amber pieces were sampled with the help of local amateur palaeontologists at an only temporarily accessible outcrop (road construction works). Amber was only found in lignitic (dark, carbon rich) lenses within grey coloured clay in the initial digging site Garnache 1 but not in other nearby outcrops with similar lithology (Néraudeau et al., 2017). The stratigraphic correlation and dating of the sediment that contained the amber yielded severe difficulties, namely the inaccessibility of Garnache 1 and the insufficient resolution of the local geological map (Néraudeau et al., 2017). Néraudeau et al. (2017) used palynomorphs from Garnache 1 to date the amber bearing sediment by (relative) biostratigraphy. Based on their results they suggested a Turonian (Late Cretaceous) age for the sediment. The Turonian is correlated with an absolute age of 93.9 to 89.8 million years (Ogg et al., 2012, International Chronostratigraphic Chart v. 2018/08). Chemical analyses of the amber matrix favoured Cupressaceae related trees as the origin of the now fossilised resin (Nohra et al., 2015; Néraudeau et al., 2017).

The sediment surrounding the Vendean amber pieces was most likely deposited in an estuarine or lagoonal coastal environment within the Challans-Commequiers Basin (Néraudeau et al., 2017). Charentese amber of Southwest France is slightly older (latest Albian-earliest Cenomanian) and comes from a different geological basin (Aquitaine Basin) (Perrichot et al., 2010). The slightly older Albian (Early Cretaceous) "Iberian amber" was found in northern and eastern Spain (Penalver and Delclòs, 2010). Despite the spatial proximity today, the Iberian basins and the French basins with (arthropod bearing) Cretaceous amber do not directly correspond as they represent coastal regions of separated landmasses in the Cretaceous. Iberian amber comes from a series of geological basins (mainly Basque-Cantabrian Basin and Maestrat Basin) roughly portraying the coastline of the Iberian terrane during the Cretaceous (Penalver and Delclòs, 2010). Charentese amber (Aquitaine Basin) and Vendean amber were deposited in basins along the west coast of the European archipelago and are linked to coastal depositional environments including marine or brackish waterbodies near the amber trees (Girard et al., 2008; Perrichot et al., 2010; Saint Martin et al., 2015; Néraudeau et al., 2017). All Iberian amber localities are, just like Vendean amber, associated with lignitic sediments deposited in deltaic or estuarine environments and, in the case of the Basque-Cantabrian Basin (El Soplao), also with marine influence (Penalver and Delclòs, 2010).

Vendean amber, although the sample size is very limited, has already yielded a diverse spectrum of fossil arthropod species. A complete list is given in Néraudeau et al. (2017). Aquatic inclusions known in Vendean amber (apart from the herein described epicaridean crustaceans) are a water mite ("Hydracarina"), centric diatoms and one tanaidacean crustacean (Peracarida: Tanaidacea) (Saint Martin et al., 2015; Sánchez-García et al., 2016; Néraudeau et al., 2017).

\section{MATERIAL AND METHODS}

\section{Material and Repository}

The focus of this study is small epicaridean isopod specimens preserved in amber. The fossils are embedded in 17 pieces of Vendean amber. Vendean amber refers to Cretaceous amber found in the department of Vendée, France (Figure 4), which comprises a small collection of amber pieces found in the outcrop Garnache 1 (coordinates: $46^{\circ} 52.802$ ' N $1^{\circ} 51.583^{\prime}$ W., elevation $12 \mathrm{~m}$ ). Vendean amber is dated to a Turonian (Late Cretaceous) age (93.9 to 89.8 million years old) (Néraudeau et al., 2017). The amber pieces studied herein originate from the private collection of Fanny Dupé, which has been donated to the collection of the Geological Department and Museum of the University Rennes 1 (IGR.GAR-8.1-1, IGR.GAR-8.1-2, IGR.GAR-8.2, IGR.GAR-28, IGR.GAR-41-1, IGR.GAR-41-2, IGR.GAR-48, IGR.GAR-51, IGR.GAR-53-1, IGR.GAR-53-2, IGR.GAR-64, IGR.GAR-65, IGR.GAR-89, IGR.GAR-90, IGR.GAR-92, IGR.GAR-93, IGR.GAR-94, IGR.GAR-95-1, IGR.GAR-95-2, IGR.GAR-97, IGR.GAR-98). Each piece contained either one or two visible larvae. Altogether the studied amber pieces bear 21 visible inclusions of epicarideans (see Appendix 1 for a more detailed description of the amber pieces).

The pieces were manually polished using a Buehler Metaserv 3000 polisher and Buehler CarbiMet silicon carbide papers to remove the altered, opaque outer surface of the amber samples. Whenever possible, a further polishing was made 


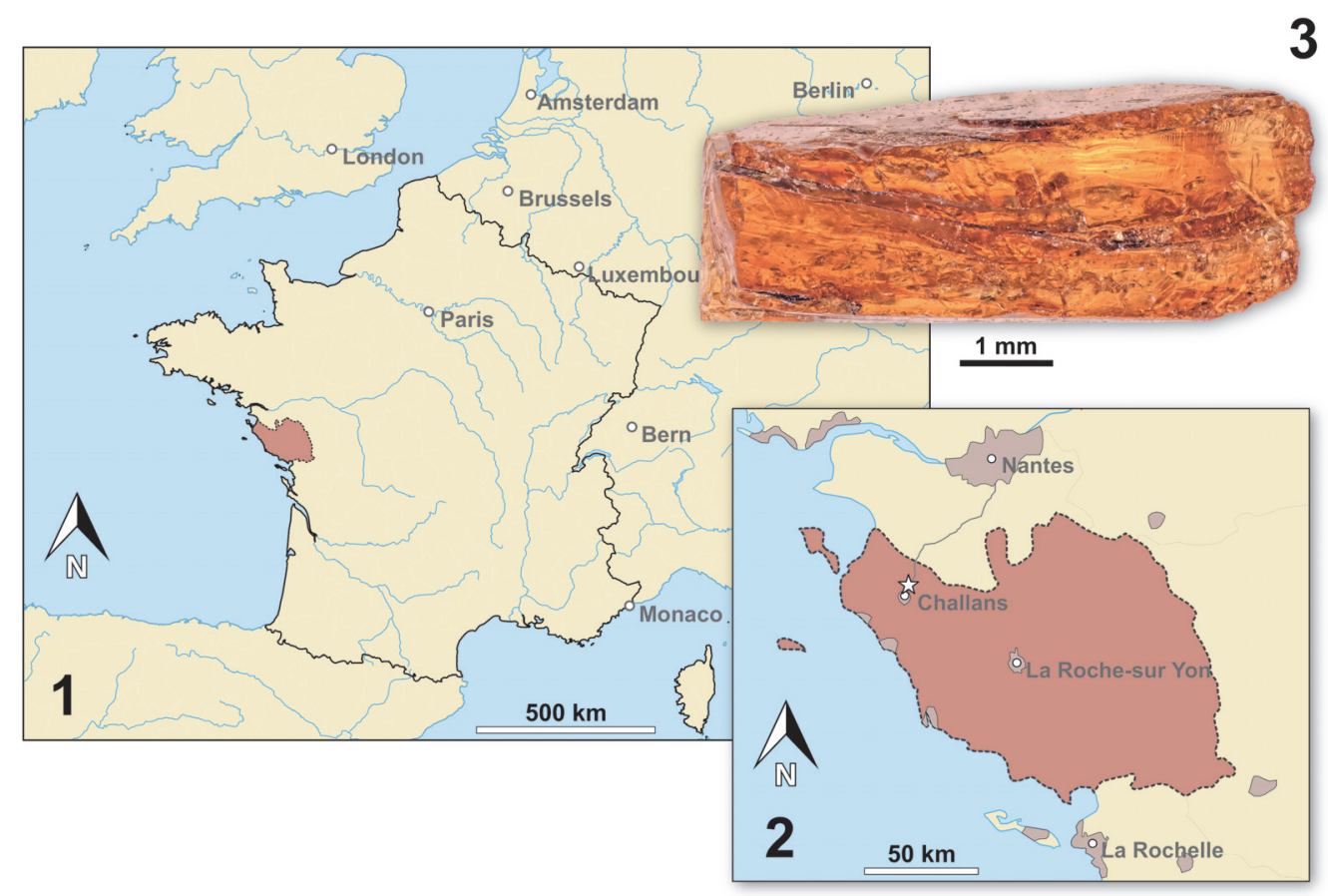

FIGURE 4. Map of France (4.1) and a detailed map of the Vendée department (reddish) (4.2). The fossil site is marked by a star. 4.3: Photograph of a piece of Vendean amber - notice the layered build-up of the resin.

to obtain flat surfaces for optimal observation and imaging of the inclusions. Some pieces that contained multiple inclusions were cut using a scalpel blade as a microsaw in order to separate the syninclusions and facilitate their respective study.

\section{Referencing}

To precisely address each specimen (more than one specimen can occur with the same collection number) we amended the collection number with the suffix "-1" or "-2". A distinction between two neighbouring specimens is warranted by a study of the photographic images (Figures 5-9) and a description of the preservational circumstances of each specimen (Appendix 1).

\section{Documentation Methods}

Imaging was performed with a Keyence BZ9000 epi-fluorescence inverted microscope and a Keyence VHX-6000 digital microscope with a 20$2000 x$ lens. The pieces of amber were photographed fully submerged in water (fluorescence microscopy) or dry or partly wetted with a cover slip on top. For the fluorescence microscopy we experienced the best results using incident light with an excitation wavelength centre of $545 \mathrm{~nm}$ (generally used for rhodamine-based stains, 'TRITC' filter cube).
For some of the images gathered with the Keyence VHX-6000 digital microscope, the implemented focus-stacking method was used to create in-focus images. In all other cases, stacks of unprocessed images were saved for later customized image processing.

\section{Image Processing}

Using the VHX-6000 digital microscope the internal stacking algorithm was used for focusstacking for some images. Additionally, single images were separately merged with CombineZP (Alan Hadley, GPL) for better results. Fluorescent microscopy images were also separately merged using CombineZP and Macrofusion/EnfuseGUI (both based on the Enfuse image blending algorithm, GPL). Panoramic image compositions were stitched "manually" in GIMP (GNU Image Project) or automatically stitched in Hugins (based on Enfuse and Enblend, GPL). The microphotographs were post-processed in GIMP and arranged and labeled in Inkscape (GPL). Graphs were plotted in $R$ and manually adjusted in Inkscape without actions that could alter the position of data points relative to each other or the axes. Drawings and schemes were created in Inkscape and post processed in GIMP roughly applying the approach proposed by Coleman (2003). 

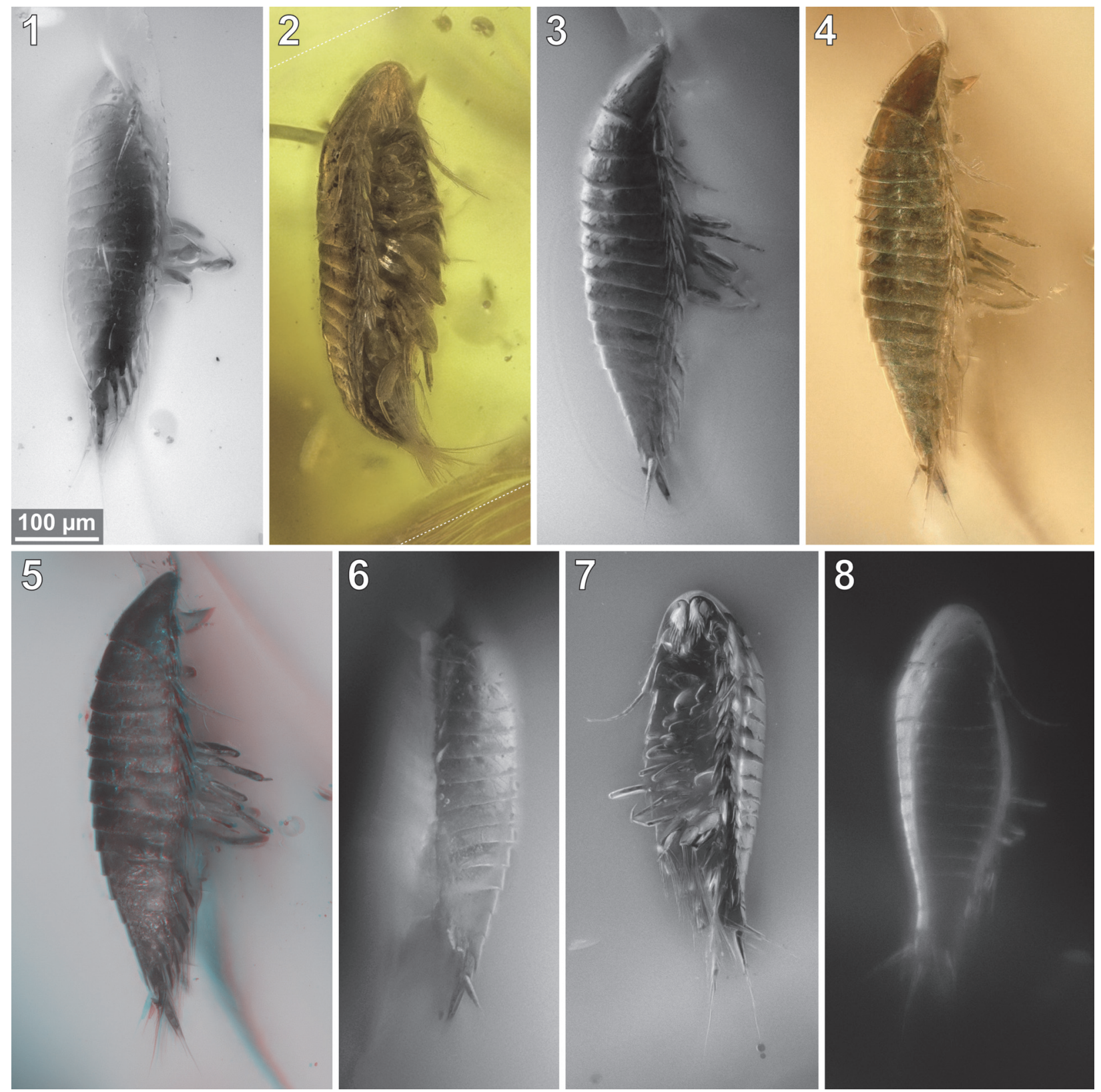

FIGURE 5. Vacuotheca dupeorum sp. nov., comparative overview of the type material sorted by collection number (same scale). 5.1: Paratype IGR.GAR-8.1-1, lateral view, epifluorescence. 5.2: Paratype IGR.GAR-8.1-2, latero-ventral view, reflected light. 5.3-5.6: Paratype IGR.GAR-8.2, lateral view (5.3-5.5) and lateral view of the opposite side (5.6), epifluorescence $(5.3,5.6)$, reflected light (5.4) and 3D red-cyan anaglyph of reflected light micrograph (5.5). 5.75.8: Holotype IGR.GAR-28, ventro-lateral view (5.7) and dorsal view (5.8), epifluorescence.

Phylogenetic trees in Figure 2 were created in $R$ (ape, phytools and paleotree) from a manually written edge matrix, converted to a phylo-object and then both converted to a single "cophylo"object. The final plot was afterwards adjusted and styled in Inkscape.

A phylogenetic tree, figured below, to illustrate character distributions among epicarideans, is based on the molecular phylogeny of Boyko et al. (2013) and the assignment to (genus-ranked) higher groups (Boyko et al., 2008). The tree topology was created with a manually written edge matrix in a spreadsheet file and converted to a phylo-object in $\mathrm{R}$ (ape and phylobase). The final plot along with matching character states (Appendix 2) was generated using the phylo.heatmap 

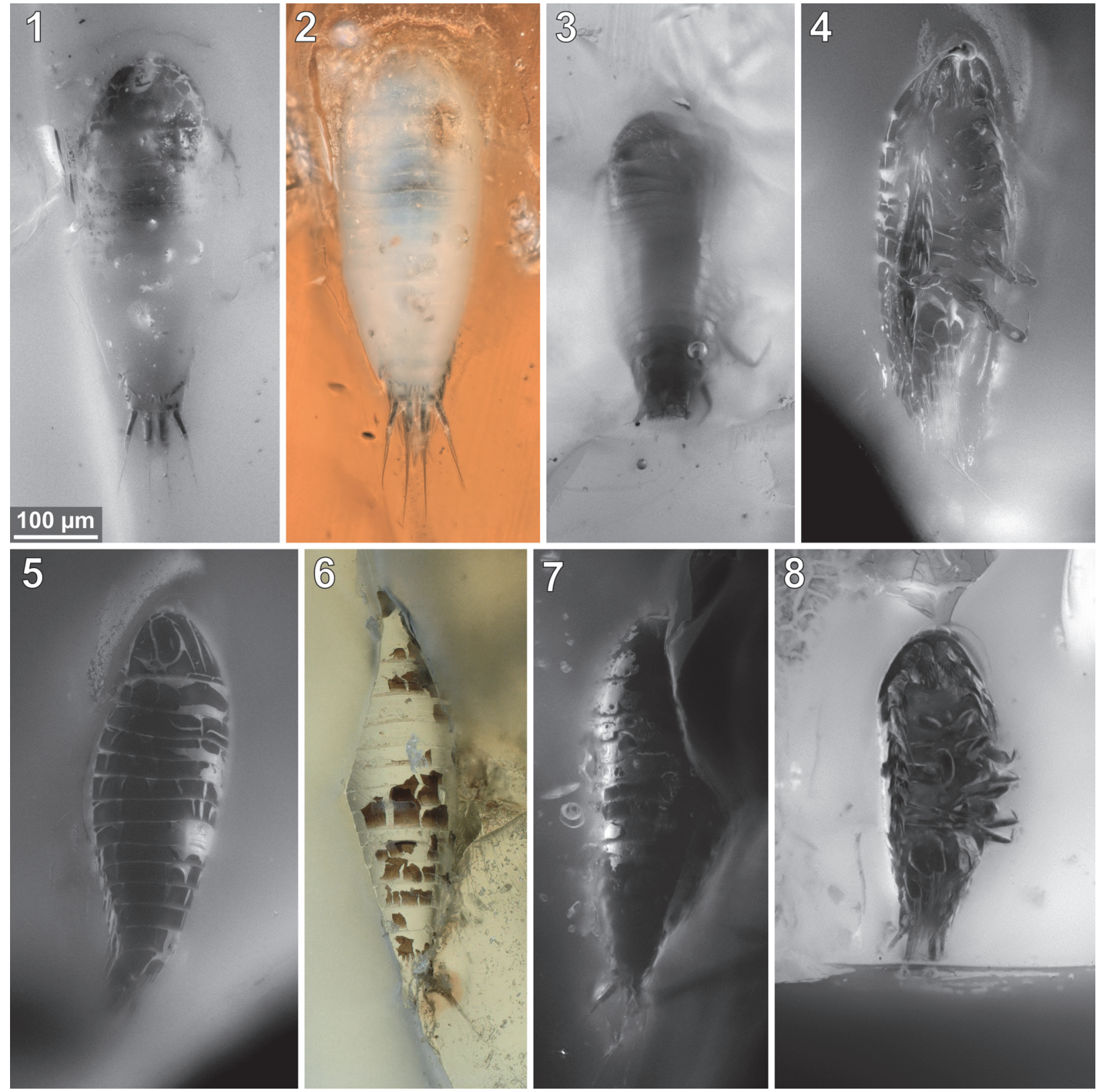

FIGURE 6. Vacuotheca dupeorum sp. nov., comparative overview of the type material sorted by collection number (same scale). 6.1-6.2: Paratype IGR.GAR-41-1, dorsal view, epifluorescence (6.1) and reflected light (6.2). 6.3: Paratype IGR.GAR-41-2, dorsal view, epifluorescence. 6.4-6.5: Paratype IGR.GAR-48, ventrolateral view (6.4) and dorsal view (6.5). 6.6-6.7: Paratype IGR.GAR-51, located at the surface of the amber piece and cracked in roughly frontal plane, ventral view of the dorsal surface (6.6) and dorsal view (6.7), reflected light (6.6) and epifluorescence (6.7). 6.8: Paratype IGR.GAR-53-1, ventral view, epifluorescence.

function from the phytools package (Revell, 2017) and adjusted in Inkscape.

\section{Measurements}

Lengths of cryptoniscium larvae (Appendix 3) were collected from the literature or measured from scaled figures. If not declared otherwise, the body length is measured from the anterior-most point of the head-shield to the posterior-most point of the pleotelson (posteriormost tergite fused with telson). The correction for the z-depth (three-dimensional orientation of the specimens in the resin) was done by examination of the original stack of unprocessed images. The spatial distances between the focal planes of the images are uniform and could be extracted from the microscope. Thus, by count- 

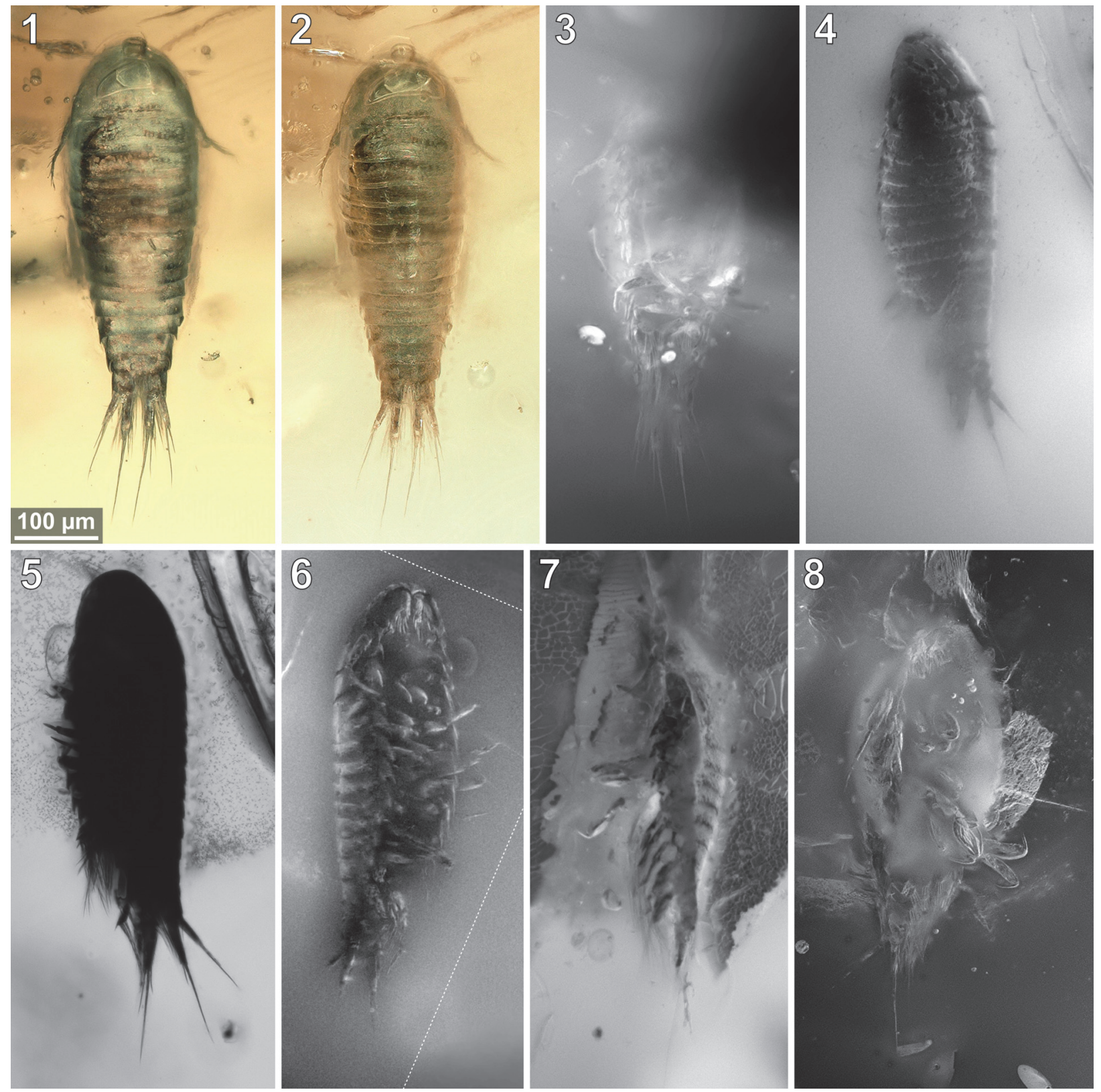

FIGURE 7. Vacuotheca dupeorum sp. nov., comparative overview of the type material sorted by collection number (same scale). 7.1-7.3: Paratype IGR.GAR-53-2, dorsal view (7.1, 7.2) and ventral view (7.3), reflected light with (7.1) and without (7.2) polarising filter and epifluorescence (7.3). 7.4-7.6: Paratype IGR.GAR-64, dorso-lateral view (7.4) and ventro-lateral view $(7.5,7.6)$, epifluorescence $(7.4,7.6)$ and transmitted light (7.5). 7.7: Paratype IGR.GAR-65, lateral view, epifluorescence. 7.8: Paratype IGR.GAR-89, ventro-lateral view, epifluorescence. Dashed lines mark areas with artificially created background.

ing interjacent images between structures in focus (defined and known pitches) the z-depth could be determined.

\section{Nomenclature}

The body of isopod crustaceans is organised into 20 segments, the ocular segment and 19 postocular segments, and the non-somitic telson. The segments form three distinct functional units or tagmata. The first seven segments form the functional head (cephalothorax) including the ocular segments and six appendage-bearing post-ocular segments (segments of antennula, antenna, mandible, maxillula, maxilla and maxilliped). The trunk is further subdivided into two tagmata. The anterior one (pereon) is formed by seven segments (post-ocular 


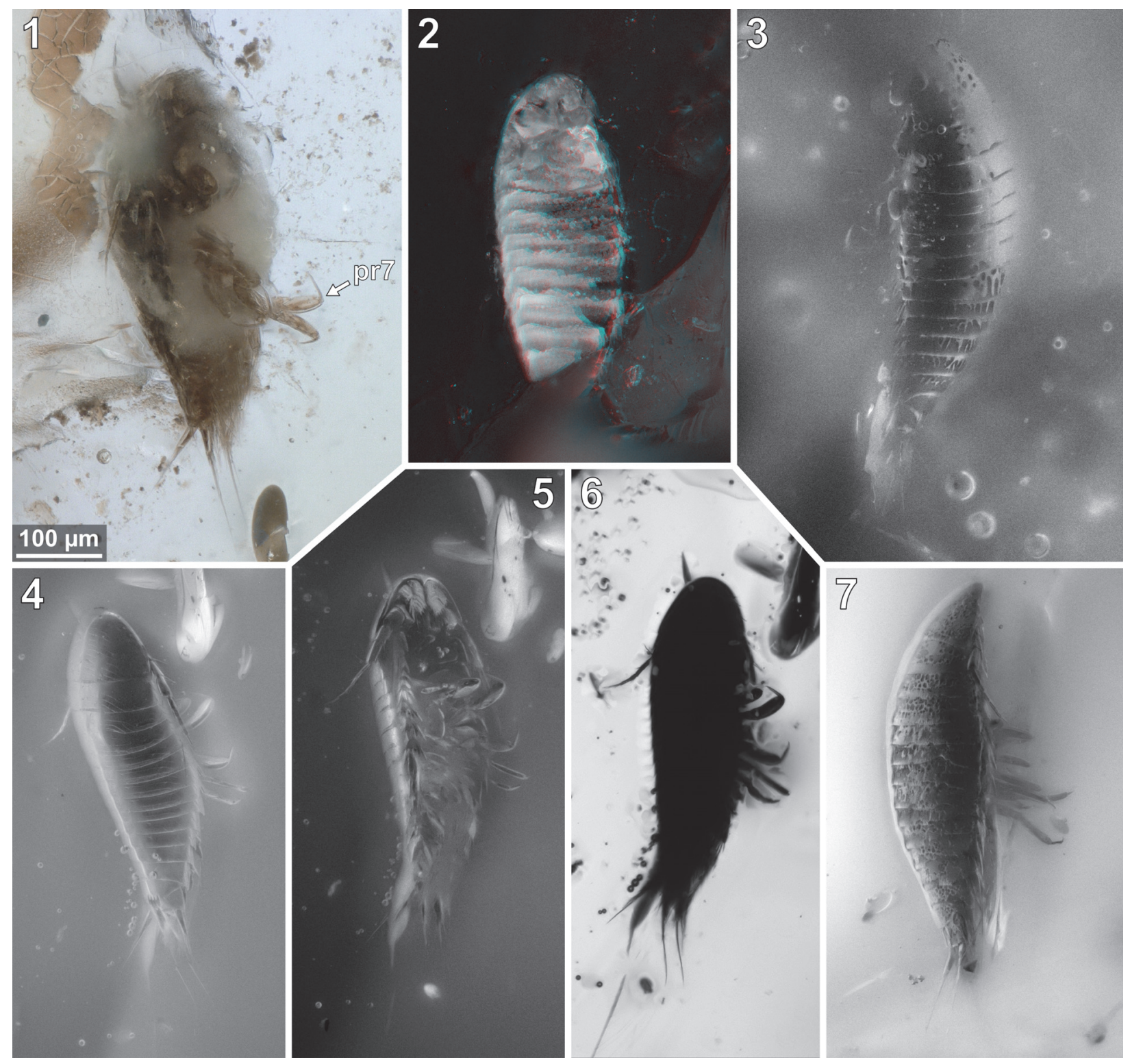

FIGURE 8. Vacuotheca dupeorum sp. nov., comparative overview of the type material sorted by collection number (same scale). 8.1: Paratype IGR.GAR-89, ventro-lateral view, reflected light; pr7, pereopod 7. 8.2: Paratype IGR.GAR-90, located at the surface of the amber piece and cracked in roughly frontal plane, ventral view of the dorsal surface, 3D red-cyan anaglyph of reflected light micrographs. 8.3: Paratype IGR.GAR-92, lateral view, epifluorescence. 8.4-8.6: dorsal view (8.4) and ventral view (8.5, 8.6), epifluorescence $(8.4,8.5)$ and transmitted light (8.6). 8.7: Paratype IGR.GAR-94, lateral view, epifluorescence.

segments 7-13); each with a separated free tergite and a pair of uniramous walking appendages (thoracic appendages, thoracopods, pereopods). The third tagma, pleon, is formed by post-ocular segments 14-19 and the telson. Pleon segments 1-5 each have a separate free tergite and a pair of biramous swimming appendages (pleopods). Pleon segment six (post-ocular segment 19) is conjoined dorsally with the telson (pleotelson) and bears a pair of biramous appendages (uropods).
We herein use the term microniscium and cryptoniscium instead of microniscus larva and cryptoniscus larva to highlight the interpretation of this morphology as a distinct ontogenetic appearance rather than referring to the historical interpretation as (genus-ranked) animal groups (e.g., "Microniscidae" in Bonnier, 1900). Our intention hereby is to use terms that have no prior charge and to be more consistent with the term epicaridium. 

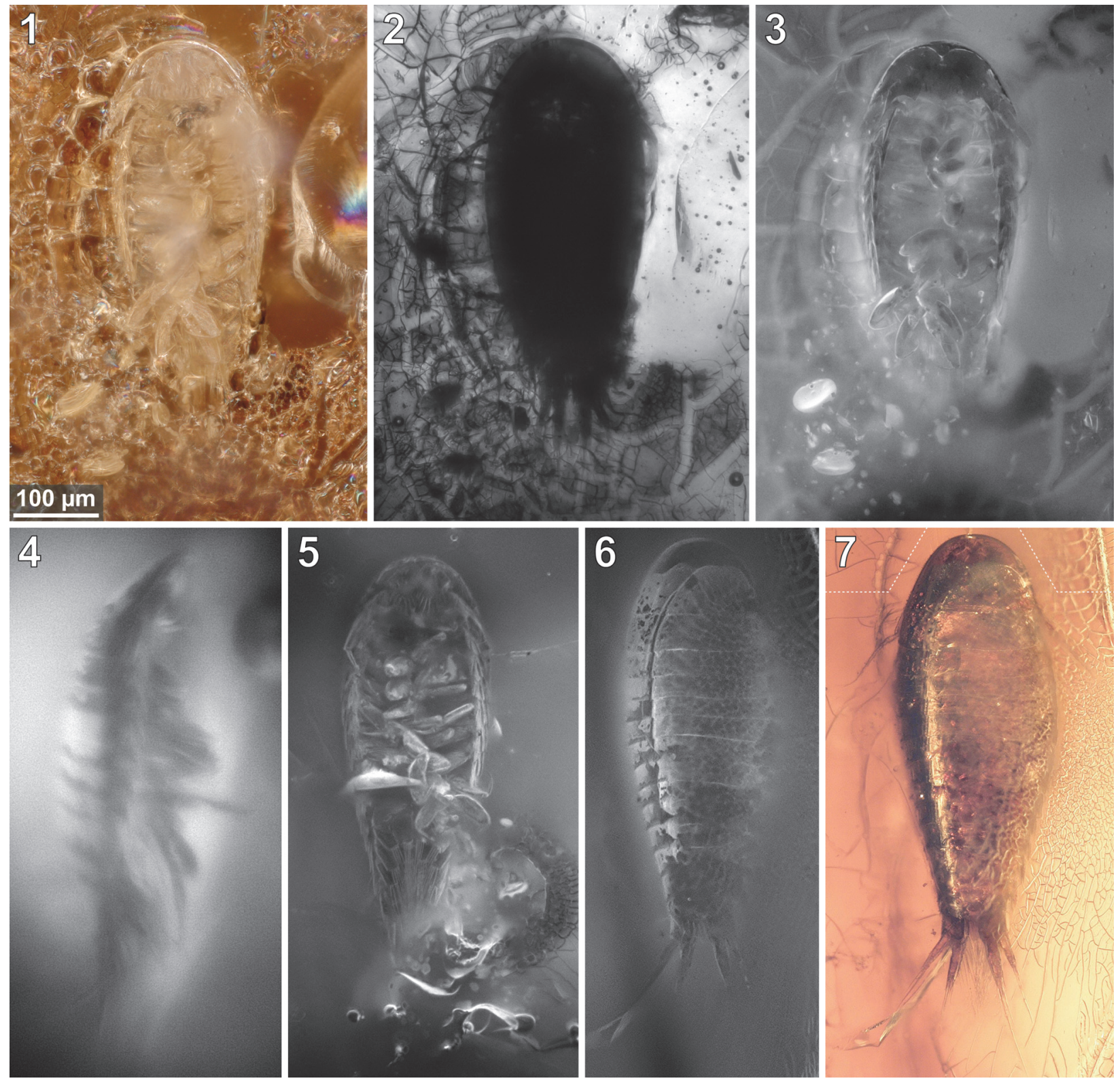

FIGURE 9. Vacuotheca dupeorum sp. nov., comparative overview of the type material sorted by collection number (same scale). 9.1-9.3: Paratype IGR.GAR-95-1, ventral view, reflected light (9.1), transmitted light (9.2) and epifluorescence (9.3). 9.4: Paratype IGR.GAR-95-2, lateral view, epifluorescence. 9.5: Paratype IGR.GAR-97, ventral view, epifluorescence. 9.6-9.7: Paratype IGR.GAR-98, dorsal view, epifluorescence (9.6) and reflected light (9.7). Dashed lines mark areas with artificially created background.

In most cases where the terms microniscium and cryptoniscium have been used many authors did use incorrect plural forms. The correct plural form of microniscium is microniscia and for cryptoniscium is cryptoniscia (second/o-stem declension in a neuter case).

\section{Taxonomic Practice}

The International Code of Zoological Nomenclature (ICZN) recommends (no strict regulation) to write genus and species names in italic letters with the intention to separate the (binominal) species name from 'higher taxa' (ICZN 2012, App. B, 6.). However, in our view this is problematic because the genus, besides its function as part of the species name, also ideally represents a natural group (when not monospecific). Therefore we suggest writing generic names in italics when they are used as part of the species name but writing in regular letters when they are used to address natural 

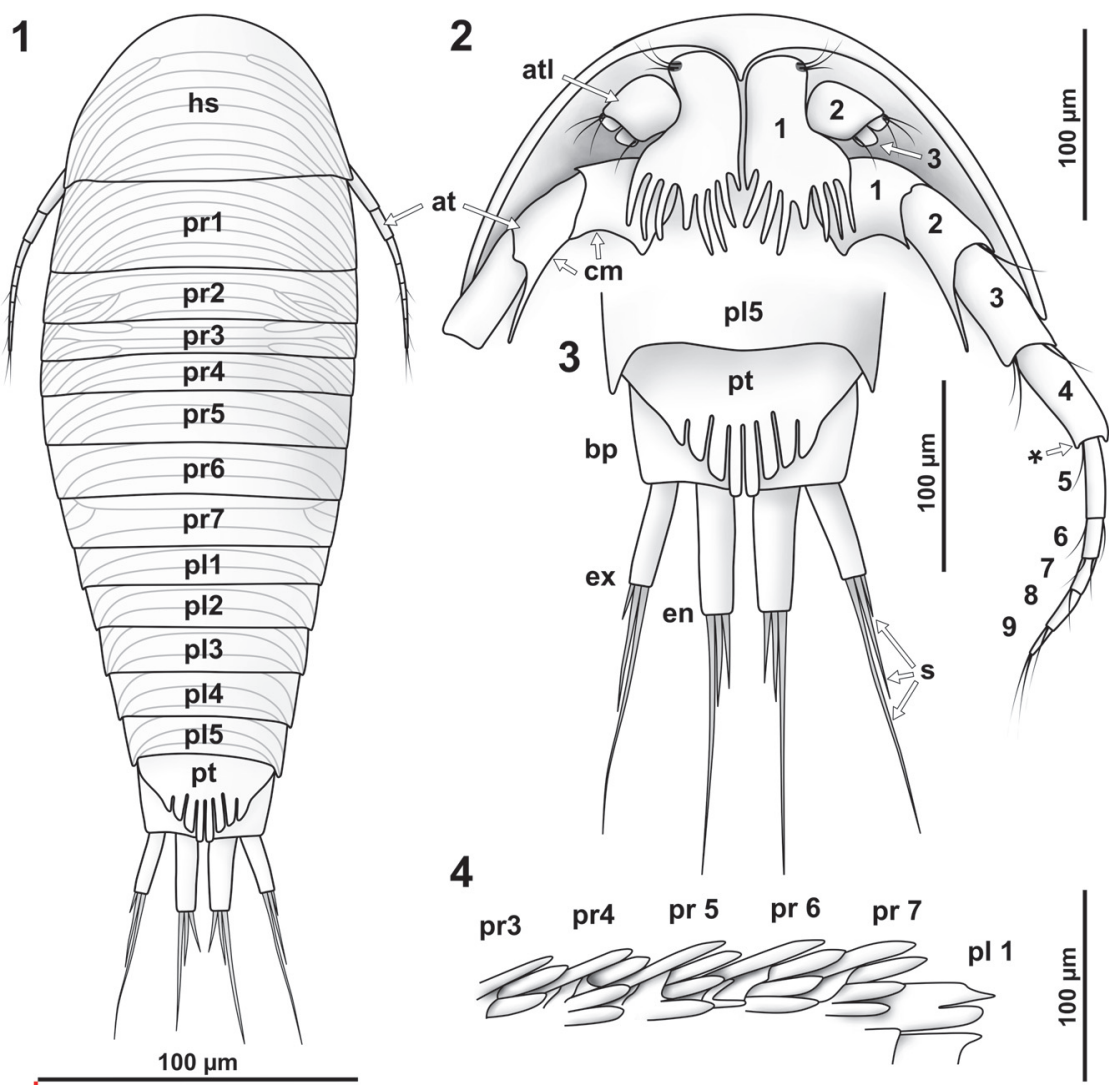

FIGURE 10. Vacuotheca dupeorum sp. nov., reconstructions and drawings. 10.1: Reconstruction in dorsal view (based on multiple specimens) including the striation pattern (based on paratype IGR.GAR-93). 10.2: Reconstruction based on paratype IGR.GAR-95-1 and holotype IGR.GAR-28, head shield in ventral view, numbers refer to the elements of antennula (numbers on the left side) and antenna (numbers on the right side). 10.3: Drawing of the paratype IGR.GAR-41-1, uropod region in dorsal view. bs, basipod of the uropod; en, endopod of the uropod; ex, exopod of the uropod; pl5, pleon segment 5; pt, pleotelson (pleon segment 6 and telson). Drawing of the holotype IGR.GAR-28, coxal plates in ventro-lateral view, mirrored. per3-per7, pereon segments 3-7; pl1, pleon segment 1.

groups (e.g., the groundpattern of Drosophila). This should help the reader to differentiate between references to species vs. references to groups.

\section{RESULTS}

\section{Summarizing Description}

This description is based on multiple specimens (Figures 5-9). To warrant the traceability between characters and specimens, described characters are followed by an abbreviated reference to the specimens in which the described features were observed: e.g.,"IGR.GAR-8.1 specimen 2 " is cited as "[8.1-2]". We tried to cover all characters that were recommended for future descriptions proposed by Nielsen and Strömberg $(1965,1973)$ wherever it was possible.

\section{General Body Form}

The general body form is strictly bilateral with the anterior-posterior body axis being the longest [all specimens]. The dorsal surface is convex with greatest dorsal-ventral extent at about half of the overall body length (Figure 5.4) [8.1-1, 8.2, 28, 48, $64,92,93,94,95-2]$. The dorsal outline of the complete body (without appendages) is ovate to dropshaped with the broadest point at about the half of the body length and tapering posteriorly (Figures $7.1,10.1)[41-1,41-2,53-2,95-1,97,98]$. The ventral side of the animal (without appendages) is concave, and the resulting space is occupied by the appendages (Figure 5.7) [8.1-2, 28, 48, 53-1, 64, $89,93,95-1,95-2,97]$. The overall size of the main body (excluding anterior and posterior appendages, i.e., antennula and uropods) ranges from $366 \mu \mathrm{m}$ [53-1] to $495 \mu \mathrm{m}$ [8.2] with a mean of 423 

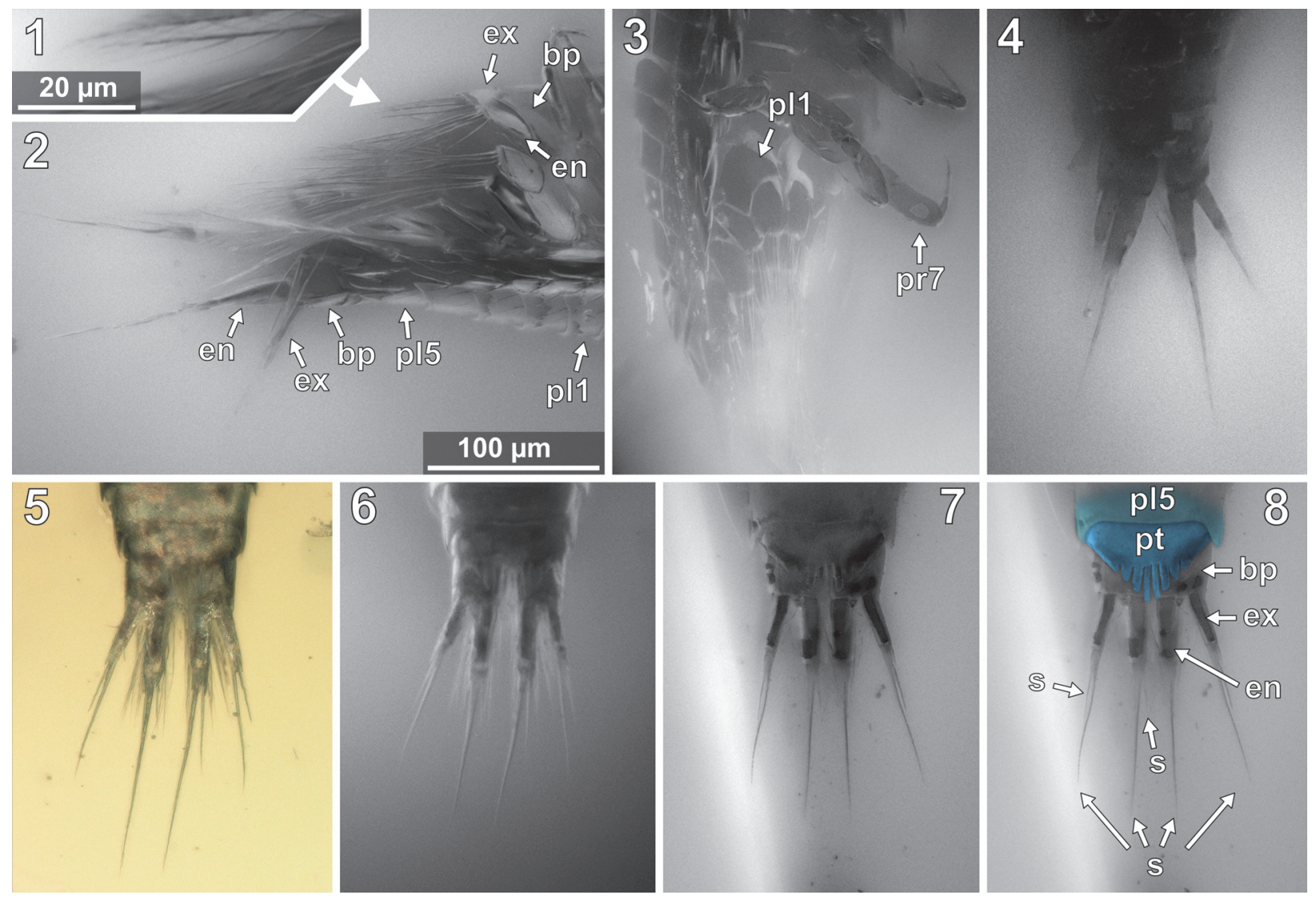

FIGURE 11. Vacuotheca dupeorum sp. nov., detailed images of the pleon and the uropod region (11.2-11.8 with same scale). 11.1: Holotype IGR.GAR-28, setulose setae on pleopod 1, ventro-lateral view, epifluorescence. 11.2: Holotype IGR.GAR-28, pleon and uropods in ventro-lateral view, epifluorescence. bas, basipod of pleopod 1; en, endopod of the pleopod 1; ex, exopod of the pleopod 1; pl1 and pl5, pleopod segment 1 and 5; up, uropod segment. 11.3: Paratype IGR.GAR-48, pleon region in ventral view, epifluorescence. pr7, propodus of pereopod 7. 11.4: Paratype IGR.GAR-64, uropod region in dorsal view, epifluorescence. 11.5-11.6: Paratype IGR.GAR-53-2, uropod region in dorsal view, reflected light (11.4) and epifluorescence (11.5). 11.7 - 11.8: Paratype IGR.GAR-41, uropod region in dorsal view, epifluorescence. bas, basipod of the uropod; en, endopod of the uropod; ex, exopod of the uropod; pl5, pleon segment 5; pt, pleotelson (pleon segment 6 and telson); st, setae.

$\mu \mathrm{m}$ and a corresponding standard deviation of 32 $\mu \mathrm{m}$.

\section{Dorsal Sclerites}

Dorsal areas of the ocular segment and postocular segments 1-6 (segments of antennula, antenna, mandibula, maxillula, maxilla and maxilliped) form a single dorsal sclerite, head shield. The dorsal surfaces of the post-ocular segments 718 (trunk segments 1-12) form free tergites. [8.1-1, 8.2, 28, 41-1, 48, 53-2, 64, 92, 93, 94]. The tergite of the post-ocular segment 19 (pleon segment 6 , uropod segment) is conjoined with the telson [8.2, $41-1,48,53-2,64,92,93,94,98]$ forming a pleotelson that is roughly triangular in dorsal view (Figures $10.3,7.1,11.8)$. The pleotelson has a rounded posterior corner and a toothed posterior margin
$[41-1,48,53-2,64,93,98]$ bearing six straight posterior pointed teeth with blunt tips (Figure 11.611.8) [41-1, 53].

\section{Head Shield}

The anterior margin of the head shield is almost half-circular in dorsal view (Figure 6.1-2) [41-1, 41-2, 53-2, 64, 95-1, 98]. The head shield has a convex dorsal surface, and its ventral margins lie in one plane (Figure 5.4). A median posterior-pointed extension protrudes from the anterior margin of the head shield forming a triangular ventral plain surface and corresponding to lateral concave lateral spaces that are occupied by the antennulae (Figure 12.1) [8.1-2, 28, 48, 53-1, 64, 93, 95-1, 97]. 


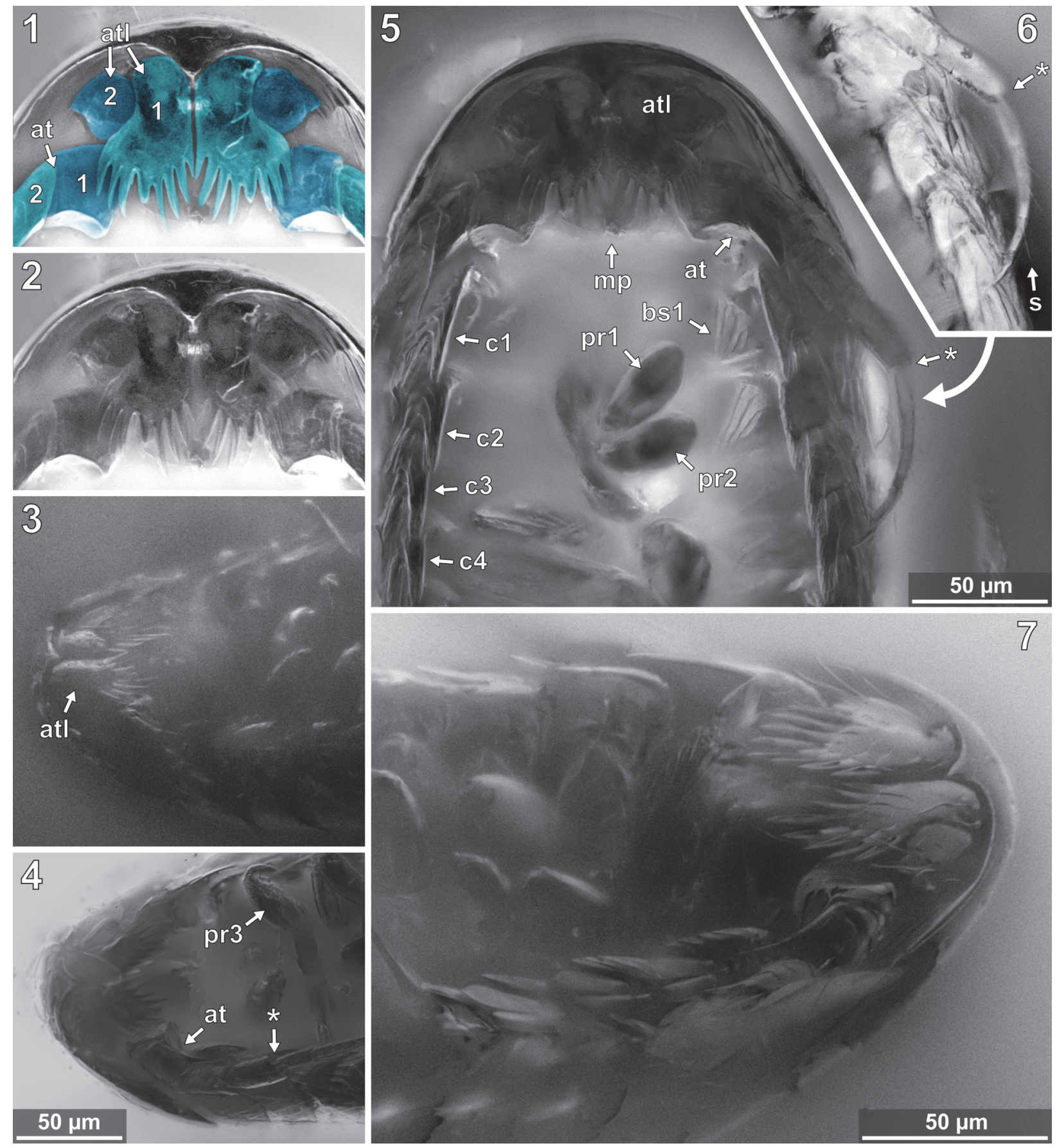

FIGURE 12. Vacuotheca dupeorum sp. nov., detailed images of the head region. 12.1-12.2: Paratype IGR.GAR-95-1, head region in ventral view, epifluorescence, numbers refer to the elements of antennula (atl) and antenna (ant), in blue colour (12.1), same scale as 12.4. 12.3: Paratype IGR.GAR-64, head region in ventro-lateral view, epifluorescence, same scale as 12.4. 12.4: Paratype IGR.GAR-53-1, head region in ventro-lateral view, epifluorescence. pr3, propodus of pereopod 3; *, junction between antennal peduncle and flagellum (element 4 and element 5). 12.5-12.6: Paratype IGR.GAR-95-1, head and pereon region in ventral view (12.5) and distal antenna elements in ventral view (12.6), epifluorescence, same scale. bs1, basipod of pereopod 1; cp1-cp4, coxal plates of pereon segments 1 to 4; dc1-dc2, dactsyli of pereopods 1 and 2; $\mathbf{m p}$, mouthparts; s, seta. 12.7: Holotype IGR.GAR-28, head region in ventrolateral view, epifluorescence, compare to 10.2 for identification of details. 


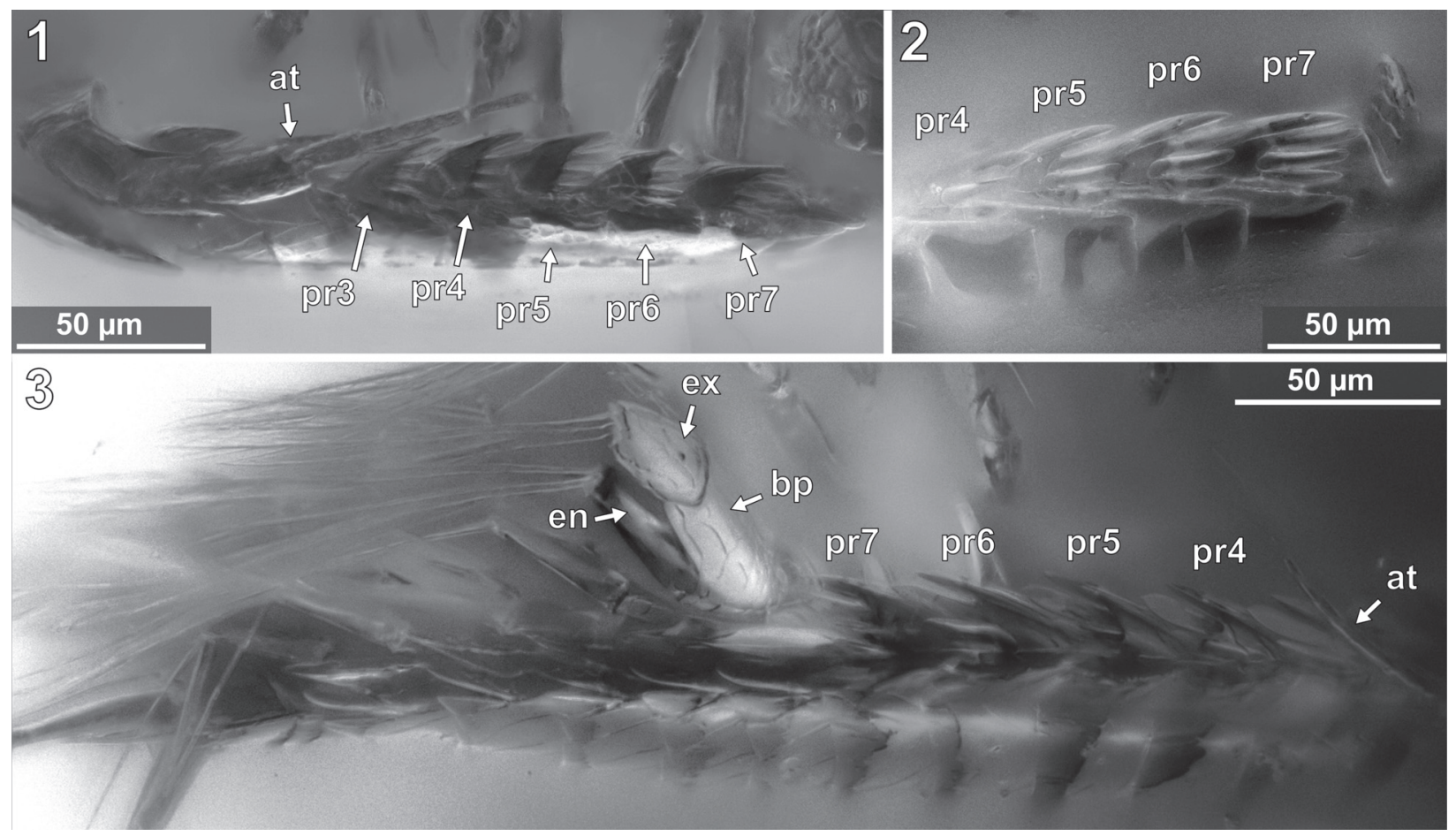

FIGURE 13. Vacuotheca dupeorum sp. nov., detailed images of the lateral body side. 13.1: Paratype IGR.GAR-53-1, ventro-lateral view, epifluorescence. at, antenna; pr3-pr7, pereopod segments 3 to 7, arrows point to the corresponding coxal plates. 13.2: Paratype IGR.GAR-48, ventro-lateral view, epifluorescence. 13.3: Holotype IGR.GAR-28, ventro-lateral view, epifluorescence. bp, basipod of pleopod 1; en, endopod of pleopod 1; ex, exopod of pleopod 1.

Eye-structures are not apparent [8.1-1, 8.2, 28, 41-1, 48, 53-2, 64, 92, 93, 94, 98]. However, this must not necessarily mean that the living animal possessed no optical sensory organs (see discussion).

\section{Tergites}

The tergites have a convex dorsal surface, which anteriorly conforms with the head-shield. The preservation of the tergite surfaces is variable. In some specimens it appears smooth (Figure 5.4) $[8.2,28,41-1,48,93,98]$. In other specimens the smooth surface is disrupted by large extensive or multiple small crater-like gaps (Figure 8.7) [8.1-1, $41-1,51,65,94]$, which can appear darker or brighter with respect to the fluorescent characteristics of the surrounding surface areas. One specimen shows a fluent transition between the small and large gaps on the dorsal surface (Figure 8.3) [92].

In some of the specimens a striation pattern is visible, which consists of more or less parallel sometimes bifurcating lines, which appear brighter or darker under fluorescent light than the surrounding surface areas (Figure 8.4, 10.1) [8.2, 41-2, 48, $53-2,92,93,98]$. The striation has some variation between the specimens. Also, the position of the specimens and their accessibility by microscopy preclude further statement about the bilateral symmetry of the striation. The striation pattern is also preserved in specimens where the organic matter of the specimen is separated from the amber matrix (shrinking). Here, the surface of cavity in the resin bears the morphological information of the (putative) original surface of the animal. The striation pattern is thus depicted by the light refraction of the amber surface, which has kept it as a counterpart (Figure 6.6) $[48,51]$. The ventro-lateral margins of the tergites of the pleon segments each have two pointed lobes directing posterior (Figure 13.3) $[8.1-2,28,48,53-1,94]$.

\section{Antennula}

The antennula (appendage of post-ocular segment 1) consists of three peduncle elements and two flagella (Figures 10.2, 12.1-2) [28, 93, 95]. The first element has a large plate-like posteriororiented extension bearing multiple teeth on its distal margin; the anterior margin is continuous and without a plate-like extension [8.1-2, 28, 48, 53-1, $64,89,93,95-1,97]$. The first antennula element bears three setae antero-laterally and distally, all 
arising close to each other (Figures 10.2, 12.2, 12.7, Appendix 4) $[28,48,93,95]$. The functional ventral surface (originally anterior) of the antennula plates has sharp furrows that correspond to the proximal origins of the posterior pointing teeth of the posterior expansion of the first antennular element (Figure 12.7) [28, 93]. There are eight teeth on the plate-like posterior-oriented extension of the first antennula element in all specimens (where counting was possible) (Figures 10.2, 12.2, 12.3, $12.4,12.7)[28,53-1,64,95]$.

Element two is about as long as element one (without extension) and is roughly quadratic in ventral view [28, 53-1, 95]. Element two lacks teeth and plate-like extensions (Figures 10.2, 12.1-12.2) [28, 48, 53-1, 93, 95].

A presumably present third antennular element is not discernible from the microscopic photographs. It is the third element that usually bears two distal flagella, which are also apparent here. Each flagellum consists of a single element [28, 93, 95]. The anterior flagellum bears three delicate setae and the posterior flagellum bears at least one delicate seta (Appendix 4) [28].

\section{Antenna}

The antenna (appendage of post-ocular segment 1) is composed of nine elements, coxa, basipod and seven endopod elements, functionally organised into four peduncle elements $[28,53,93$, 95-1] and five flagellum elements (Figures 10.2, $12.5,12.6)[8.1-1,8.1-2,8.2,28,53-1,53-2,89$, $93,94,95-1]$. In dorsal view the first two peduncle elements are always concealed by the body, and the third antennal element protrudes from the postero-lateral corner of the head shield (Figure 7.1) $[8.1-1,8.1-2,8.2,28,64,41-1,41-2,53-1,53-2$, $90,93,95-1,97,98]$.

The peduncle elements are distinctly wider than the flagellum elements [8.1-1, 8.1-2, 8.2, 28, 41-1, 41-2, 53-1, 53-2, 48, 93, 94, 95-1, 97]. Element one and two (coxa and basipod) together form a continuous concave median (functional posterior) margin that distally ends in the spine-like prolonged postero-distal corner of the second element (Figure 10.2, 12.4, 12.5) [28, 53-1, 95]. Element two bears at least one seta distally at its anterior (functional ventral) side. Element three bears three setae distally on the ventral side. Element 4 bears at least one seta distally on its anterior (functional ventral) side (Figure 10.2, Appendix 4 and 5) [28, 53-1].

The flagellum elements are barrel shaped to slightly conical and decrease in diameter distally
(Figure 12.6) [8.1-1, 8.1-2, 8.2, 28, 53-1, 89, 93, $94,98]$. Fifth antennal element (proximal flagellum article) with two distal setae (Figure 10.2) [8.1-1]; sixth element with at least one distal seta [53-2, 93, 95]; seventh element with two distal setae [8.1-1, 28]; eighth element with one distal seta [8.1-1, 53$2,28]$; ninth (distal-most) element with two distal setae (Figure 10.2, Appendix 4) [28, 53-2].

\section{Mouthparts}

The mouthparts (appendages of post-ocular segments 3-6; mandible, maxillula, maxilla, maxilliped) form a posteroventral-pointing cone (Figure 12.5) $[28,53,93,95]$. The cone is concealed by an anterior larger sclerite that encompasses about two thirds of the perimeter of the cone and a smaller triangular posterior sclerite (only visible in the original stack of images, Appendix 4) [28, 53]. The cone is apically truncated with a narrow opening (Figure 12.2, Appendix 4) [28, 53, 95-1].

\section{Pereopods (appendages of the pereon segments/post-ocular segments 7-13)}

Each of the seven free thoracic segments bears a pair of appendages (pereopods). Each consists of seven elements. Element one, coxa, forms a plate like structure that lies in extension to the lateral margin of its corresponding tergite (coxal plates). Coxal plates bear posterior teeth (Figures 10.4, 13.2) [8.1-2, 8.2, 28, 48, 53-1, 89, $93,95-1,95-2,97]$. All coxal plates have four teeth (in specimens where the preservation allowed for counting) [28, 48, 53-1, 64]. Posterior to the coxal plates, in the pleon segments, are lateral extensions of the tergites that superficially resemble the coxal plate morphology (see description of tergites, Figure 13.3).

Element two (basipod) is large. Element three (ischium) is slightly shorter. Elements four and five (merus, carpus) are short. Element six (propodus) is large. Element seven (dactylus) is spine-like and slightly curved inwards. The thoracic appendages become progressively longer towards the posterior end of the body. The first two pereopods are both short, the third is longer, the fourth even more. The fifth pereopod is longer than the fourth and about as long or only slightly shorter than pereopods 6 and 7 , which are the longest and about the same length (Figure 14.2, 15) [53-1].

Pereopod 1. The basipod is broad and with a concave space at the median side (Figure 12.5, 12.7 14.1) [28]. The propodus is broad and only weakly anterior-posteriorly compressed with an oval outline in anterior view (Figure 12.5, 14.1) [28, 53-1, 

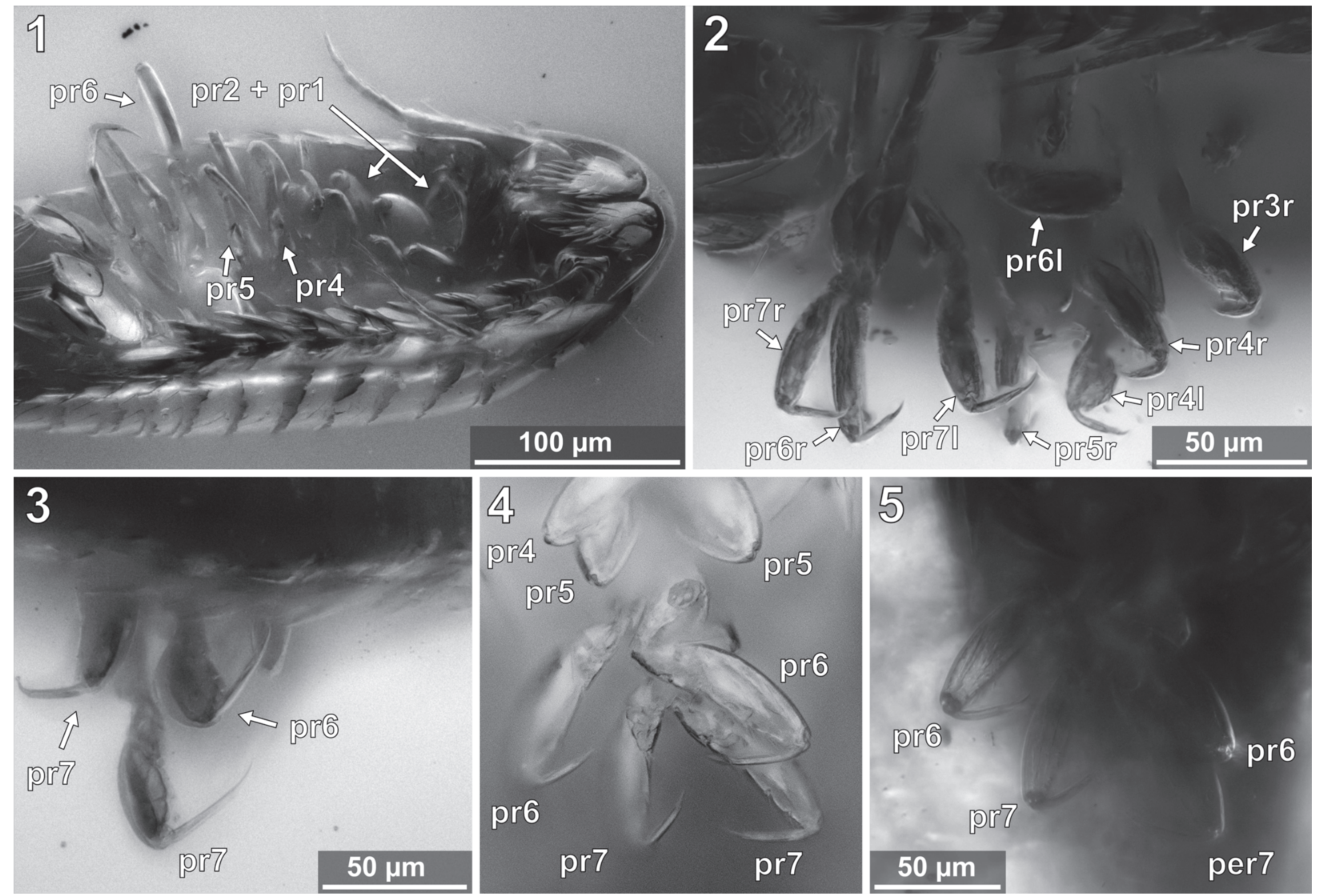

FIGURE 14. Vacuotheca dupeorum sp. nov., detailed images of the pereopods. 14.1: Holotype IGR.GAR-28, ventrolateral view, epifluorescence. pr1-2 and pr4-6, pereopods 1-2 and 4-6. 14.2: Paratype IGR.GAR-53-1, pereopods in lateral view, right side of the image is anterior, epifluorescence, for labels see Figure 15 (corresponding drawing with labels). 14.3: Paratype IGR.GAR-8.1-1, posterior pereopods in lateral view, right side of the image is anterior, epifluorescence. pr6-pr7, pereopods 6 and 7. 14.4-14.5: Paratype IGR.GAR-95-1, pereopods in ventral view, upper side of the image is anterior, same scale. pr4-pr7, pereopods 4 to 7.

95-1], the median margin of the propodus is distally with a soft angle. The dactylus is curved inward and with a pointed tip (Figure 14.1).

Pereopod 2. The propodus is weakly compressed in anterior-posterior axis, with an oval in outline in anterior view (Figure 14.1) [28, 53-1, 95-1], the median margin of the propodus is distally with a soft angle.

Pereopod 3. The basipod is long and slender, much narrower than in pereopod 1 (Figures 14-15) [53-1]; the propodus is weakly compressed in anterior-posterior axis, with an oval outline in anterior view (Figures 14-15) [28, 53-1, 95-1], the median margin of the propodus is distally with a soft angle and a set of two setae distal to the angle (Figure 12.4) [28, 53-1, 95-1]. The dactylus is curved inward and with a pointed tip (Figures 14-15).

Pereopod 4. The basipod is long and slender, much narrower than in pereopod 1 (Figures 14-15) [53-1]. The propodus is compressed in anteriorposterior axis (Figure 14.1) (resulting in an even anterior and posterior surface) and longer and narrower as that of pereopods 1-3, the median margin of the propodus is distally with a distinct soft angle and a set of two setae distal to the angle (Figures 14-15) [28, 53-1, 95-1]. The dactylus is slightly curved inward and with a pointed tip (Figure 14.12).

Pereopod 5. The basipod is long and slender, much narrower than in pereopod 1 (Figures 14-15) [53-1]. The propodus is compressed in anteriorposterior axis (resulting in an even anterior and posterior surface) and longer and narrower as that of pereopods 1-3 (Figure 14.1), the median margin is distally with a set of two setae [28, 53-1, 95-1]. The dactylus is slightly curved inward and with a pointed tip (Figure 14.4).

Pereopod 6. The basipod is long and slender, much narrower than in pereopod 1 (Figures 14-15) [53-1]. The ischium is compressed in anterior-posterior axis with a convex lateral margin and a straight median margin (Figures 14-15) [53-1]. The 


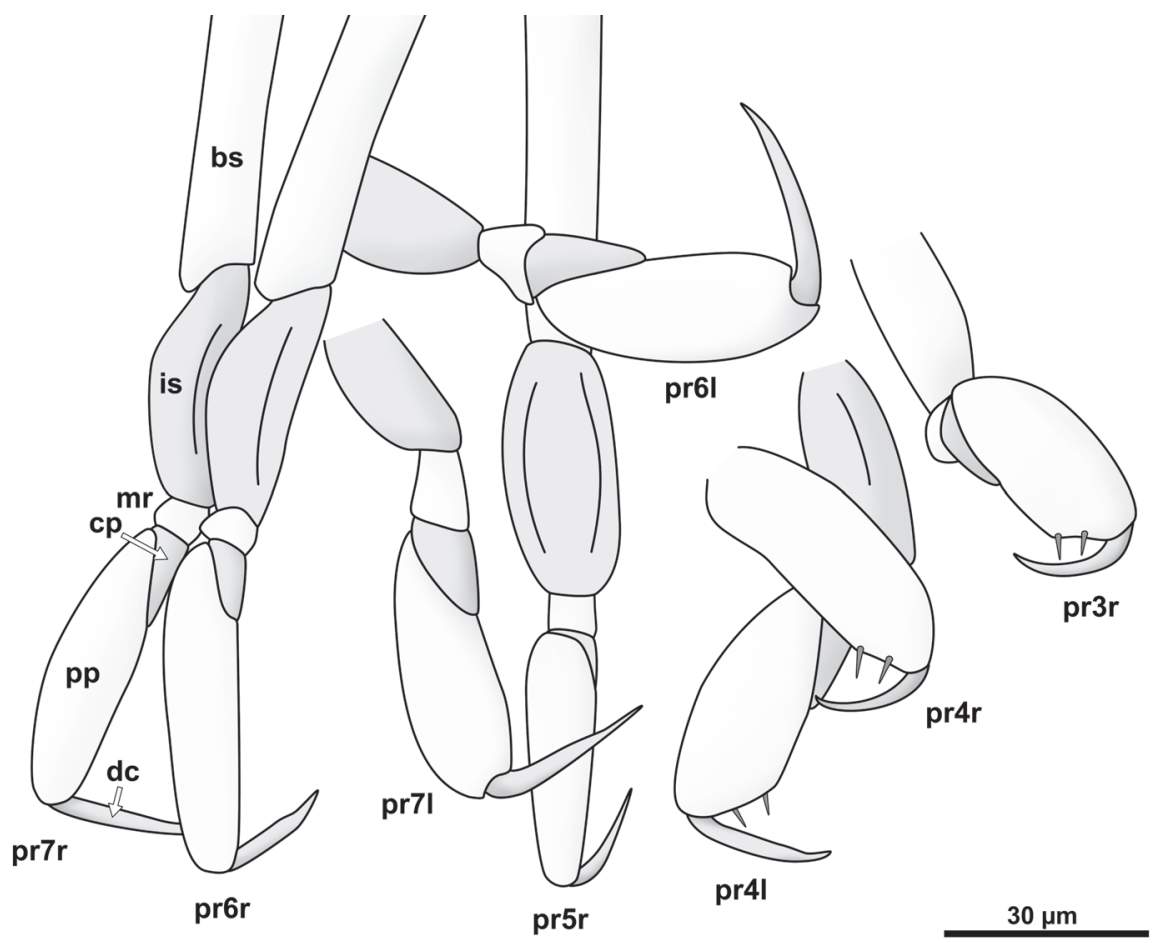

FIGURE 15. Vacuotheca dupeorum sp. nov., paratype IGR.GAR-53-1, drawing of pereopods 3 to 7 (pr3-pr7). (r), right body side; (I), left body side; bs, basipod; is, ischium; mr, merus; cp, carpus; pr, propodus; dc, dactylus. Notice the setae on the propodi of pereopods 3 and 4.

merus is short and roughly triangular in anterior view (Figures 14-15) [53-1, 89, 95-1]. The carpus is short and roughly triangular in anterior view (Figures 14-15) [53-1, 89, 95-1]. The propodus is antero-posteriorly compressed (resulting in an even anterior and posterior surface) and longer and narrower as that of pereopods 1-3 (Figure 14.1), the median margin is distally with a set of two setae [28, 53-1, 95-1] and with two proximodistal strings of muscles distally attaching to the lateral and median side of the dactylus joint (Figure 14.5) [89, 95-1]. The dactylus is slightly curved inward and with a pointed tip.

Pereopod 7. The basipod is long and slender, much narrower than in pereopod 1 (Figures 14-15) [53-1]. The ischium is anterior-posteriorly compressed with a convex lateral margin and a straight median margin (Figures 14-15) [53-1]. The merus is short and roughly triangular in anterior view (Figures 14-15) [53-1, 89, 95-1]. The carpus is short and roughly triangular in anterior view (Figures 1415) [53-1, 89, 95-1]. The propodus is antero-posteriorly compressed (resulting in an even anterior and posterior surface) and longer and narrower as that of pereopods $1-3$, the median margin is distally with a set of two setae (Figure 14.4) [28, 53-1, 951] and with two proximo-distal strings of muscles distally attaching to the lateral and median side of the dactylus joint (Figure 8.1) [89, 95-1]. The dactylus is slightly curved and with a pointed tip (Figure 14.3).

\section{Pleopods (appendages of the pleon segments/ post-ocular segments 14-18)}

The pleopods consist of a broad basipod which distally bears the median endopod and the lateral exopod (Figures 13.3, 11.2) [28, 48, 53-1, 97]. All elements are strongly compressed in anterior-posterior axis and roughly leaf-shaped. The endopods are broader and more massive than the corresponding exopods [28, 48, 53-1, 97].

Endopod and exopod bear long setae distally (Figure 11.2) [8.1-1, 8.1-2, 8.2, 28, 48, 53-1, 53-2, $64,89,97]$. The setae originate in an obtuse angle from the pleopods and point posteriorly (Figure 11.2) [8.1-1, 28, 64]. Pleopod 1 is with at least five setae on the endopod and four setae on the exopod (Figure 11.2) [28]. Pleopod 2 is with at least five setae on the exopod [28]. Pleopod 3 is with at least three setae on the endopod and four setae on the exopod (Figure 11.2) [28].

At least in pleopods 1 , the distal setae are setulose with delicate posterio-laterally protruding setulae. The setulae are less than $1 \mu \mathrm{m}$ in diameter and ca. $15 \mu \mathrm{m}$ long (Figure 11.1) [28]. 


\section{Uropod (appendage of post-ocular segment 19)}

The uropods consist of a basipod which distally bears the median endopod and the lateral exopod. The basipod of the uropods is massive and rectangular in dorso-ventral view [8.1-1, 41-1, 41-2, 53-1, 53-2, 64, 93, 98]. Basipods are apparently movable in relation to the trunk as specimens with (parallel) posterior pointed (Figure 11.7) [41-1, 41-2, 53-2] and somewhat spread (laterally diverging) basipods (Figure 11.4) [64, 98] suggest. Endopods and exopods are truncated cone-shaped (tapering distally). Endopods and exopods are apparently movable in relation to the basipod as the angle between both elements and the angle between each of the elements and the corresponding basipod vary in one specimen (Figure 11.4). Endo- and exopods are ovate to rectangular in cross-section (greatest diameter in dorsoventral direction) (Figure 6.3) [41-2]. The endopods are longer and thicker than the exopods (Figure 10.3, 11.4-8) [8.1-1, 8.2, 28, 53-1, 53-2, 64, 89, 98] and distally bear one long and one short seta (Figure 11.5) [53-2]. The exopods are about as long as the basipods (Figure 10.3, 11.4-8) [8.1-1, 53-2, 64, 28] and distally bear one long (about twice as long as the exopod) and one short seta (Figures 10.3, 11.5, 11.7) [53-2].

\section{DISCUSSION}

\section{Systematic Interpretation}

Assuming that the cone shaped feeding apparatus consists of appendages of more than one segment (four segments in Epicaridea), the functional head comprises at least four appendagebearing segments, which is apomorphic for Euarthopoda (sensu Walossek, 1999, e.g., Haug et al., 2013). The trunk is divided in two distinct sets of segments (thorax and pleon), which are considered as an apomorphy of Eumalacostraca (Walossek, 1999).

The body is dorsoventrally flattened, and the tergite of the first thoracic segment (maxilliped) is conjoined with the tergites of the functional head. The lateral flagellum of the antennula is not well developed but consists only of a single short element. Also, all pereopods (appendages of postocular segments 7-13) lack an exopod. This combination of characters is unique and characterizes the group Isopoda (Ax et al., 2000; Wilson, 2009). All pereopods bear lateral plate-like extensions of the coxa (coxal plates), which is an autapomorphy of Scutocoxifera (Dreyer and Wägele, 2002). The mouthparts (mandible, maxillula, maxilla and maxil- liped) form a cone-like structure, which is only known for parasitic isopods within Cymothoida (if including Gnathiidae).

The combination of the following characters is typical for larvae of the group Epicaridea (Latreille, 1825): body elongated and drop shaped; mouthparts forming a cone like structure; antennula with enlarged first element; pereopods with large propodi and thin, spine like and often curved dactyli; truncated cone-shaped uropod rami.

Within Epicaridea, a further determination providing identifications to monophyletic groups is not possible due to the absence of undisputed apomorphies in most groups. Within Epicaridea, Dajidae (Sars, 1883) is the only group with a wellaccepted apomorphy that can be seen in the cryptoniscium stage. In Dajidae cryptoniscia have an oral cone with a conspicuous sucking disk (Bresciani, 1966; Schultz, 1975; Wägele, 1989).

Thus, the herein presented specimens can be interpreted as epicarideans that are not (latin: nec) part of the epicaridean ingroup Dajidae (Epicaridea nec Dajidae). We demonstrated that the morphology of the herein presented specimens fits perfectly with that of the cryptoniscium larvae of Epicaridea. However, the exact ontogenetic phase of the fossils cannot be determined with certainty. In some epicaridean lineages (Cryptoniscoidea) the adult male does (at least superficially) not differ morphologically from the cryptoniscium (Hosie, 2008). Therefore, the studied fossils could not only represent cryptoniscium larvae but also adult males with a paedomorphic morphology. Paedomorphic, strict-protandric males (as they occur in most cryptoniscoideans) have been recorded to switch between host animals on a regular basis to inseminate females and finally find a host that is not infected by other epicarideans where they transform into a female (Wägele, 1989).

\section{Conspecifity}

We assume conspecifity for the herein studied specimens. This is based on the lack of conspicuous morphological differences among the individuals (as lain out in the description). Also, the body size is relatively uniform with a standard deviation of $32 \mu \mathrm{m}(7.5 \%$ of the mean body size). Only the dorsal striation pattern is subject to some variation within the studied specimens (Figures 5.3, 5.4, 6.2, 6.6, 7.2, 8.3, 8.4, 9.7, 10, 14.8). However, without data on the degree of variability of the striation pattern in modern species, it is impossible to draw conclusions on the intra- and interspecific variability of this character in extinct species. 


\section{Striation}

The dorsal surface as well as various other body regions of cryptoniscium larvae bears a surface pattern that superficially appears as lines (striae/striation). In the first extensive study focusing on the surface structure of cryptoniscia using scanning electron microscopy, Nielsen and Strömberg (1973) categorized striation patterns in two types. They characterized the striae on the dorsal side of the head shield as "rather broad cuticular ridges separated by narrow furrows." Striae on other parts of the body, like the pleopod basipod, were characterized as "pectinate scales." They also perfomed transmission electron microscopy to study the structure of the striae. By this, they found the striae to affect only the epicuticle but not the endocuticle. This distinction appears somewhat arbitrary because both types of striae are purely epicuticular, and both the "pectinate scales" and the ridges and furrows are asymmetric, as the transmission electron microscopy images show. It could be possible that both types differ only (gradually) in scale, collocation and manifestation of the fringes (ctenae).

Judging from the scale of the striae it is very likely that especially a dense striation pattern appears like a homogeneous surface in light microscopy and is thus been overlooked possibly partly here, but also more generally in the literature.

The visibility of this pattern in some of the herein studied fossils is highly dependent on the illumination of the specimen (e.g., compare Figure 6.1 vs. 6.2 or 7.1 vs. 7.2 ). The striation pattern is more or less pronounced in cryptoniscia of different epicaridean groups (Nielsen and Strömberg, 1973; Hosie, 2008). To our knowledge there is no information about the intraspecific variability of the striation for modern species that would be useful for the interpretation of future fossil findings.

\section{Eyes}

Although eyes are not visible in the studied specimens, we cannot conclude their absence. In many modern cryptoniscia the compound eyes are highly reduced so that they are only recognizable as dark spots beneath the dorsal surface of the head shield (Nielsen and Strömberg, 1973). Only one extant species of epicarideans has been recorded to have cryptoniscia with externally visible eyes, as well as a single fossil specimen (Schultz, 1975; Serrano-Sánchez et al., 2016).

\section{Antennula}

Wägele (1989) suggested that the toothed posterior projection of the first antennula element (antennular plate) could be an autapomorphy for Cryptoniscoidea. Based on figures and descriptions in taxonomic literature (summarized in Figure 16), we cannot support this assumption. Indeed, at least two species with a toothed margin of the antennula plate have been interpreted as representatives of Bopyroidea (Probopyrus bithynis Richardson, 1905, in Dale and Anderson, 1982) and Leidya distorta Comalia and Panceri, 1858, in Torres Jordá, 2003).

Also, Wägele (1989) suggested that a continuous margin of the antennula plate, in contrast to a toothed margin (orange colour compared to beige colour in Figure 16) could be an autapomorphy of monophyletic group combining Asconiscidae, Crinoniscidae and Cryptoniscidae. This must be seen as distinct from cases in which antennula element one has no distinct posterior projection (red in Figure 16). We support this assumption based on our study of literature. If future phylogenetic analyses support the monophyly of this group, we recommend the erection of a proper name for this group, as well as to include the two species abyssorum Bourdon, 1981, and longicaudatus Schultz, 1975, in it, which possess this specific structure (both known from cryptoniscia only and traditionally interpreted as Cryptoniscoidea incertae sedis).

Given that the distribution of a toothed antennula plate in cryptoniscia is not restricted to a single subgroup of Epicaridea, also a different polarity of the character than proposed by Wägele (1989) has to be considered. The toothed antennula plate could represent an autapomorphy of Epicaridea that has been lost several times independently.

The orientation of the mouthparts (sucking cone) seems to constrain the shape and size of the proximal element of the antennula. This seems to affect whether or not a posterior extension of the antennular plate is developed and also, if there is a posterior expansion it seems to affect the orientation of the antennular plate. Indeed, in species that have mouthparts anteriorly directed (e.g., Probopyrus pandalicola) the median margins of the first antennula element are not parallel but diverge posteriorly.

Little intraspecific variability in epicaridean species has been recorded regarding the number of these teeth. However, a few cases of intraspecific but also intra-individual differences have been recorded (Nielsen and Strömberg, 1973). 

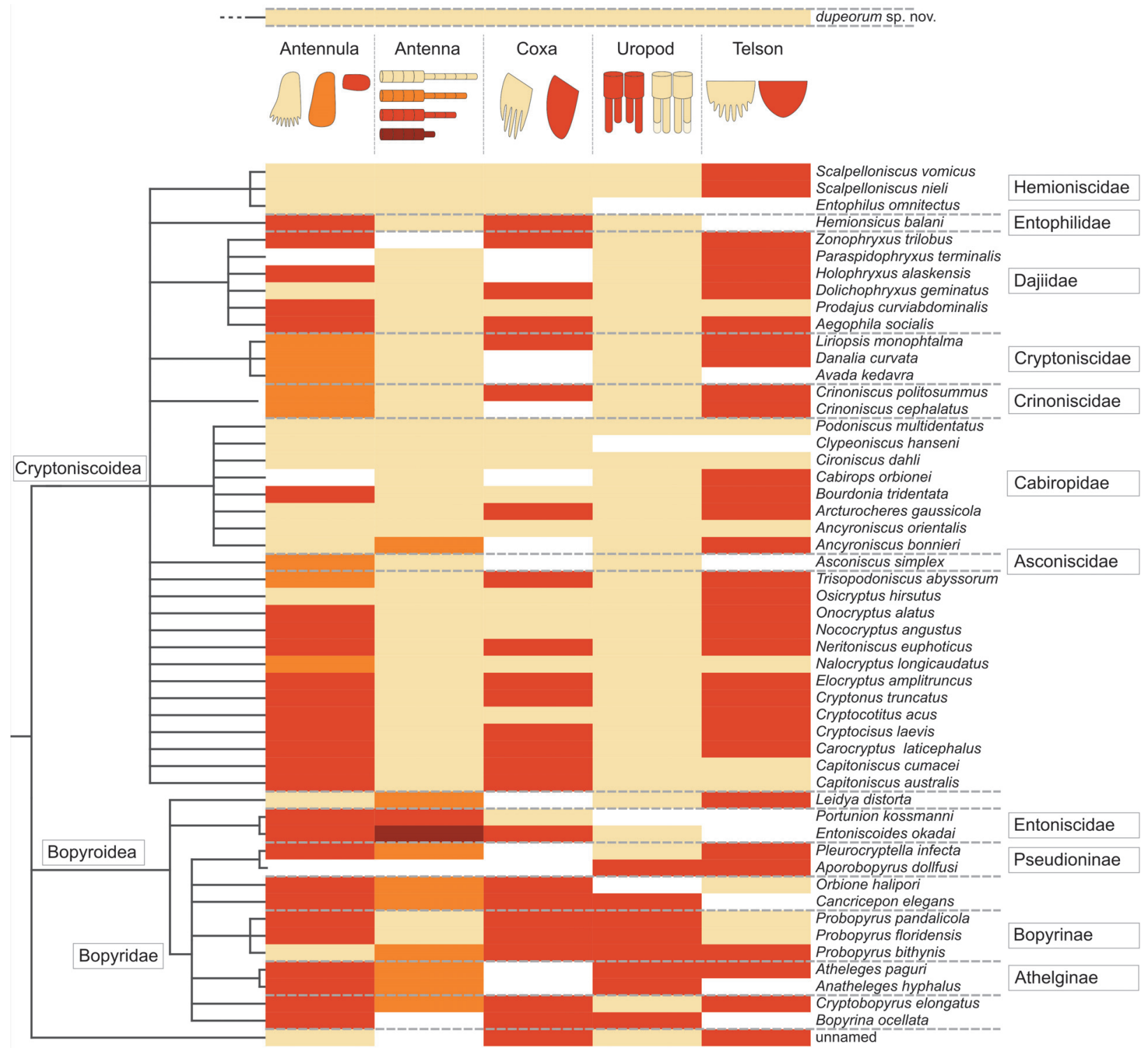

FIGURE 16. Phylogenetic tree of Epicaridea (Boyko et al., 2013) (topology on the left side, species names and taxonomic groups on the right side) mapped with characters gathered from descriptions and illustrations of literature. Characters are coded in colour as depicted in the illustration at the top. Beige is reserved for character states in Vacuotheca dupeorum gen. et sp. nov. (at the very top). Antenna: five flagellum elements (beige), four flagellum elements (orange), three flagellum elements (red), one flagellum elements (orange). Uropod: endopods longer or equal as exopods (beige), endopods shorter than exopods (red). Antennula: with posterior extension and teeth (beige), with posterior extension and without teeth (orange), without posterior extension (red). Coxa: coxal plates with teeth (beige), coxal plates without teeth (red). Telson: posterior margin with teeth (beige), posterior margin without teeth (red). (Fraisse, 1878; Giard and Bonnier, 1887; Bonnier, 1900; Thompson, 1901; Caullery, 1907; Miyashita, 1940; Nielsen and Strömberg, 1965; Bresciani, 1966; Bourdon, 1972, 1976, 1981; Holdich, 1975; Schultz, 1975, 1980; Kensley, 1979; Bourdon and Bruce, 1980; Anderson and Dale, 1981; Coyle and Mueller, 1981; Dale and Anderson, 1982; Adkinson and Collard, 1990; Rybakov, 1990; Pascual et al., 2002; Torres Jordá, 2003; Shimomura et al., 2005; Hosie, 2008; Boyko, 2015). 


\section{Antenna}

Boyko and Williams (2015) mapped the antenna morphology of cryptoniscus larvae onto their molecular phylogeny and concluded that in Cryptoniscoidea (incl. Dajidae) the number of antennal flagellum elements is five $(4+5$ antennal elements) and four (4+4 antennal elements) for Bopyridae and lonidae. In Entoniscidae they found one or three flagellum elements $(4+1$ or $4+3$ antennal elements). However, we found an exception to this pattern. Two supposed species of Bopyridae, Probopyrus pandalicola and Probopyrus floridensis, have five antennal flagellum elements (Dale and Anderson, 1982).

The cryptoniscium larvae of some species of Probopyrus are not only aberrant compared to other bopyroideans regarding the antennal morphology (floridensis and pandalicola), but also in the shape of the antennula element one (Figure 16). Probopyrus bithynis is the only bopyroidean with an antennula plate, which is posteriorly toothed and allows two possible conclusions. The distribution of character states in natural groups of Epicaridea could be more heterogeneous than expected, or the phylogenetic position of Probopyrus species is incorrect.

The situation is further complicated because of some inconsistencies in the literature. The phylogenetic trees used for the character mapping (Boyko et al., 2013, fig. 4) and (Boyko and Williams, 2015, fig. 3) show a significant discrepancy with the text. In the phylogenetic trees Cryptoniscoidea appears to be the sister group of Dajidae whereas in the text Dajidae and Entophilinae are treated as ingroups of Cryptoniscoidea. This twist in topology is based on an, incorrectly labeled, undetermined cryptoniscoidean species (in the tree 'Cryptoniscoidea' should mean 'Cryptoniscoidea sp. indet.' Also, in Boyko and Williams (2015), the key provided for the identification of cryptoniscus larvae (mainly based on antennal morphology) is erroneous as it does not allow the final identification of lonidae (although possible based on the character mapping).

\section{Mouthparts}

Due to the small size and the condensed arrangement of the mouthparts for most extant species, only descriptions of the external features of the feeding apparatus exist. The mouthparts in cryptoniscium larvae and paedomorphic males form a condensed and complex structure that has yet only been studied in detail for a single species (Goudeau, 1969, 1977). These mouth parts have many features that are unique within Isopoda. The mandibles lack a conventional proximal joint, and the arrangement of muscles suggests that an active pro- and retraction of the complete mandible is possible. However, the orientation and the external shape of the mouthparts are highly variable among epicaridean species. In many species the mouthparts form a cone-like structure often referred to as "buccal cone"; in other species the cone-like shape is less distinct. The orientation of the apical opening of the concealed mouthpartcomplex varies among epicaridean species. In some species the apical opening is located more anteriorly and can even be located medially between the proximal elements of the antennula (e.g., Probopyrus pandalicola depicted in Dale and Anderson, 1982). In Dajidae also a suction disc at the end of a short stalk occurs at the apical opening of the concealed mouthpart-complex (Wägele, 1989).

In herein presented specimens the mouthparts form a distinct cone and the apical opening of the cone points postero-ventrally (Figure 12.5, Appendix 4). In the putative sister groups of Epicaridea (Cymothoidae or Gnathiidae) the mouthparts are anteriorly projected but not between antennula and antenna. It is not clear which of these conditions is ancestral and which is derived. Comparative studies of the head morphology in larvae and adults between Epicaridea and suitable outgroups could provide information about the polarity of this character and could thus contribute to a better understanding of the phylogenetic position of Epicaridea within Cymothoida and the relationships within Epicaridea.

\section{Proximal Region of Pereopods (post-ocular segments 7-13): Coxal Plates}

Wägele (1989) interpreted the presence of coxal plates with a continuous margin as an autapomorphy for the group that comprises Asconiscidae, Crinoniscidae and Cryptoniscidae (Figure 2). It is indeed present in all species of this group, yet it is also present in many other groups (also within Cryptoniscoidea; see Figure 16).

\section{Distal Parts of Pereopods (post-ocular segments 7-13)}

Pereopods 1 and 2 (thoracic appendages 2 and 3 ) in the observed fossils are difficult to see as they do not protrude from the concave cavity in all of the specimens. Nevertheless, they are much shorter and have more robust propodi than the more posterior pereopods; which seems to be a 
pattern in extant species as well. In general, the posteriormost pereopod (pereopod 7) of cryptoniscium larvae is always the longest of the pereopods. Some modern species have a very distinct differentiation between the morphology of pereopods 1 and 2 compared to pereopods 3 to 7 . The former are usually short and robust with a short and often strongly curved dactylus and the latter long and slender with straight dactyli (e.g., Bourdonia tridentata Rybakov, 1990). In most species (e.g., Cryptocisus laevis Schultz, 1975), the antero-posterior transition between these morphologies is more gradual, which is also the case for the herein presented specimens (robust morphology of the propodi in pereopods 3 and 4, Figure 15).

In the herein presented specimens, as in many modern species, the lateral side of the propodus in the anterior-most pereopods fits into a concave space on the lateral side (medio-ventral side in tucked resting position) of the basipod (Figure 14.1). The armature of the median side of the propodus where the adducted dactylus is in contact varies among the extant cryptoniscium larvae. In the herein presented specimens two simple setae are present in pereopods 3 to 7 (Figures $14.2,15$, setae possibly also in pereopods 1 and 2 but not evident). The presence of two strong setae (often accompanied with a smaller more distal seta) is a common feature in extant species, but often additional setae are present or the setae are forked (e.g., Aegophila socialis Bresciani, 1966). This feature may be of systematic value, but small setae may have been overseen in species, which have not been studied using SEM or high magnification light-microscopy with appropriate contrasting methods.

In many descriptions of cryptoniscia a distinct tip of the dactylus has been illustrated (hardly visible here). SEM imaging (Nielsen and Strömberg, 1973, figure 43) has confirmed a distinct division between the proximal part of the dactylus (pectinate surface pattern) and the tip (smooth surface). The tip is interpreted as the claw (one of two claws in the ground pattern of Isopoda), which is curved and firmly connected to the dactylus in some groups of parasitic isopods (Wägele, 1989). In conclusion, the pereopod morphology of the herein presented specimens apparently lies within the range of modern cryptoniscia without exhibiting extreme patterns.

\section{Pleopods}

The setulose setae of the pleopods are barely visible in the processed images, except in one case (Figure 11.1) displaying convincing information after focus-stacking. The extreme delicacy of the setulae (less than $1 \mu \mathrm{m}$ in diameter) provides a good example for the exceptional preservation potential of Vendean amber. Setulose pleopod setae have been reported for some modern cryptoniscium larvae (e.g., Capitoniscus cumacei Schultz, 1975). This structure is rarely included in descriptions of extant larvae, making its systematic value difficult to assess.

\section{Uropods}

In modern cryptoniscia, endopods can be longer, equal or shorter in length to the corresponding exopods, the latter condition only being found within Bopyridae (=Bopyrinae sensu Wägele, 1989) (red in Figure 16). This could even represent an autapomorphy of Bopyridae. Manca stages of groups closely related to Epicaridea do have an endopod that is longer than the exopod (Aegidae, Cymothoidae and Gnathiidae). Note that the adults of these groups are less informative as they are often morphologically very derived and with broader and leaf-shaped endo- and exopods, which are less comparable to the truncated-coneshaped uropod rami of cryptoniscium larvae. The herein described specimens have endopods that are longer than the corresponding exopods. Combined with topological inference regarding the distribution of this character state, its presence within the herein described (oldest) fossil specimens is consistent with the ancestral feature of this length ratio.

Alternatively, Wägele (1989) suggested that uropod endopods that are longer than the corresponding exopods (in contrast to equally long endo- and exopods) could be an autapomorphy for Cryptoniscoidea. We judge this as a less parsimonious hypothesis as exopods that are longer than the endopods can be reconstructed for the ground pattern of Epicaridea. Also, the vice versa character state (endopods shorter than the exopods) is not explained by this assumption.

\section{Telson}

Judging from the literature (Figure 16) the distribution of a toothed posterior margin of the telson in cryptoniscium larvae is erratic and not linked to any natural group within Epicaridea. Considering the toothed structures on antennulae and coxal plates, we consider the possible existence of a regulatory gene complex responsible for the development of teeth-like extensions/constrictions on different parts of the body, as, if present, those pat- 
terns often occur in multiple regions of the body. One explanation for the chaotic distribution of toothed/smooth character states (Figure 16) could be that this regulatory gene complex has already been present in the ground pattern of Epicaridea, and the formation of associated teeth structures has been suppressed in many lineages.

\section{Summary of Morphological Characters and Suggested Systematic Interpretation}

Based on shared character states the herein presented specimens could be interpreted as representatives of Cabiropidae (at least two species have the exact same combination of characters that are included in Figure 16). Nevertheless, none of the character states in the herein presented specimens can be considered autapomorphic for Cabiropidae, precluding a taxonomic treatment as representatives of that group. Based on current character mapping, none of the studied character states can confidently be considered autapomorphic for any epicaridean ingroup. The herein presented specimens can therefore be treated as "Epicaridea inc. sed. nec Dajidae" (unknown position within Epicaridea but not part of Dajidae). If the antennular plate with an entire posterior margin (Wägele, 1989) is considered a strict autapomorphy of Asconiscidae+Crinoniscidae+Cryptoniscidae, then the herein presented specimens could be treated as Epicaridea inc. sed. nec Dajidae, nec Asconiscidae, nec Crinoniscidae, nec Cryptoniscidae. Yet, as discussed above, the latter assumption should be tested for consistency in future phylogenetic studies.

\section{Further Interpretations of Fossil Epicarideans from the Miocene of Chiapas}

Crustacean larvae are extremely rare in the fossil record, making this report only the second one for Epicaridea. The primary finding has been only very recently reported from the Miocene amber of Mexico (Serrano-Sánchez et al., 2016).

The authors found two clusters (specimens 1, 3,4 and 6 in contrast to specimens 2, 5a, 5b) based on the size of the specimens (Figure 17). However, the specimens of each size cluster differ enormously in the morphology of the uropods. Since these morphologies are not apparently correlating with the size clusters, Serrano-Sánchez et al. (2016) concluded that the specimens were unlikely to be conspecific within the clusters.

Specimens 1, 3 and 4 have massive and (at least in specimen 3 ) relatively long exopods but thin endopods. Specimens 2 and 6 have thin exopods and relatively long and massive endopods.

As stated above, exopods being longer and more massive than endopods is a character state found only within Bopyridae advocating for this to be autapomorphic of the group, although not as seen in by all bopyrid representatives (see discussion above). Consequently, the Mexican specimens 1,3 and 4 can be interpreted as possible representatives of Bopyridae. As Serrano-Sánchez et al. (2016) stated, these specimens must not all be conspecific.

Serrano-Sánchez et al. (2016) tentatively suggested that specimen 2 and 6 could be conspecific, specimen 6 being the corresponding microniscium larva of specimen 2 (cryptoniscium). Microniscium larvae are generally said to have ill-defined appendages without developed setae on pleopods and uropods (Anderson and Dale, 1981; Wägele, 1989), features which are clearly displayed in specimen 6. Furthermore, microniscia, due to their parasitic - non swimming - lifestyle (Anderson and Dale 1981), are quite unlikely to be preserved in amber without their host nor have they ever been reported to detach from their host.

The size clusters observed by SerranoSánchez et al. (2016) are most likely the result of the coexistence of multiple species, showing large size-ranges (e.g., 0.8-2.8 mm in Cryptocisus laevis Schultz, 1975) and possibly paedomorphic adult males resembling the cryptoniscia.

\section{Body Size}

With a mean of $423 \mu \mathrm{m}$ and the largest specimen of only $495 \mu \mathrm{m}$ in body size (excluding the uropods), the herein presented specimens are the smallest ever reported cryptoniscium larvae (Figure 17, Appendix 2) regarding both fossil and extant occurences, its average body length being even smaller than the shortest length recorded for extant species. Also, only two extant species fall within or close to the range of the herein presented specimens body size or close (Figure 17): Bopyrina ocellata, $450 \mu \mathrm{m}$ (Román-Contreras and Romero-Rodríguez, 2013) and Entoniscoides okadai, $500 \mu \mathrm{m}$ (Miyashita, 1940).

The Mexican specimens of the smaller sizecluster are slightly larger but still comparable in size to the Vendean specimen. The Mexican specimens that fall into the larger size cluster are distinctly larger than the of herein presented specimens type specimens. Nevertheless, the specimens in the larger Miocene size class are rather small compared to the spectrum of body 


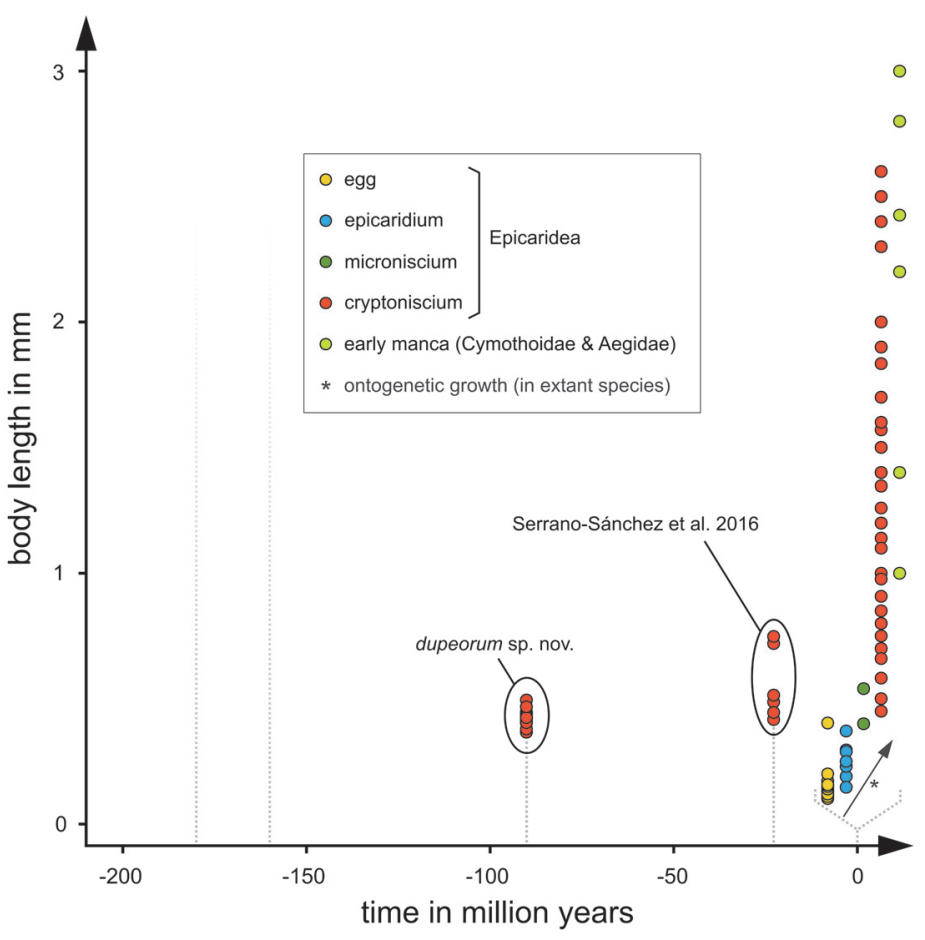

FIGURE 17. Body lengths of fossil epicaridean cryptoniscium larvae over time (all specimens) compared to cryptoniscium larvae and other developmental stages of modern epicaridean species and potential sistergroup taxa (smallest record of each species). The fading dotted lines at the left mark the earliest occurrences of trace fossils (precarious and affirmed) (Soergel, 1913; Klompmaker et al., 2014). The data from extant species is expanded for better visibility and is outlined by a dotted bracket. (Fraisse, 1878; Bonnier, 1900; Thompson, 1901; Caullery, 1907; Miyashita, 1940; Nielsen and Strömberg, 1965; Bresciani, 1966; Nielsen, 1967; Bourdon, 1972, 1972, 1976, 1981; Holdich, 1975; Schultz, 1975, 1980; Kensley, 1979; Bourdon and Bruce, 1980; Anderson and Dale, 1981; Coyle and Mueller, 1981; Dale and Anderson, 1982; Strömberg, 1983; Adkinson and Collard, 1990; Rybakov, 1990; Shields and Ward, 1998; Pascual et al., 2002; Torres Jordá, 2003; Shimomura et al., 2005; Hosie, 2008; Román-Contreras and RomeroRodríguez, 2013; An et al., 2015; Serrano-Sánchez et al., 2016; Adlard and Lester, 1995; Atkins, 1933; Bruce, 2009; Brusca, 1978; McDermott, 2002; Romero-Rodríguez and Román-Contreras, 2008; Strömberg, 1971; Thamban et al., 2015; Truesdale and Mermilliod, 1977; Tsukamoto, 1981).

lengths in cryptoniscium larvae of extant species. The body size of modern cryptoniscia extends up to $2.6 \mathrm{~mm}$ (Cryptocotitus acus Schultz, 1975), which is more than five times longer than in herein presented specimens (longest specimen).

Epicaridea being a well-supported monophyletic group (Boyko et al., 2013), the small size of the fossils compared to the wide range in size for extant species questions the ancestral size of the epicaridean cryptoniscium. Although fossil data are limited here, the most parsimonious hypothesis suggests the ancestral larva were small and that body size has increased over time in some lineages.

The size of the cryptoniscium has to be influenced by the size of the intermediate host (copepod) that is parasitised by the microniscium stage. Although some calanoid copepods are much larger, most species are of 0.5 to $2 \mathrm{~mm}$ in length
(Blaxter et al., 1998). Over time, an optimisation of the interaction between the microniscium larvae, and their hosts (copepods) could have led to a greater uptake of nutrients and the possibility for epicarideans to develop larger cryptoniscium larvae.

\section{Evolutionary History of Epicarideans}

The evolutionary history of the epicaridean lifestyle is still unresolved. Phylogenetic analyses support a close relationship with fish parasites, implying a fish-parasitic (or at least fish-associated) lifestyle for the common ancestor shared either with gnathiids (Brusca and Wilson, 1991; Brandt and Poore, 2003), cymothoids (Wägele, 1989; Dreyer and Wägele, 2001, 2002; Brandt and Poore, 2003) or both of these groups (Nagler et al., 2017). Dreyer and Wägele (2001) even suspected the possible sessile (attached) habit of the adult 


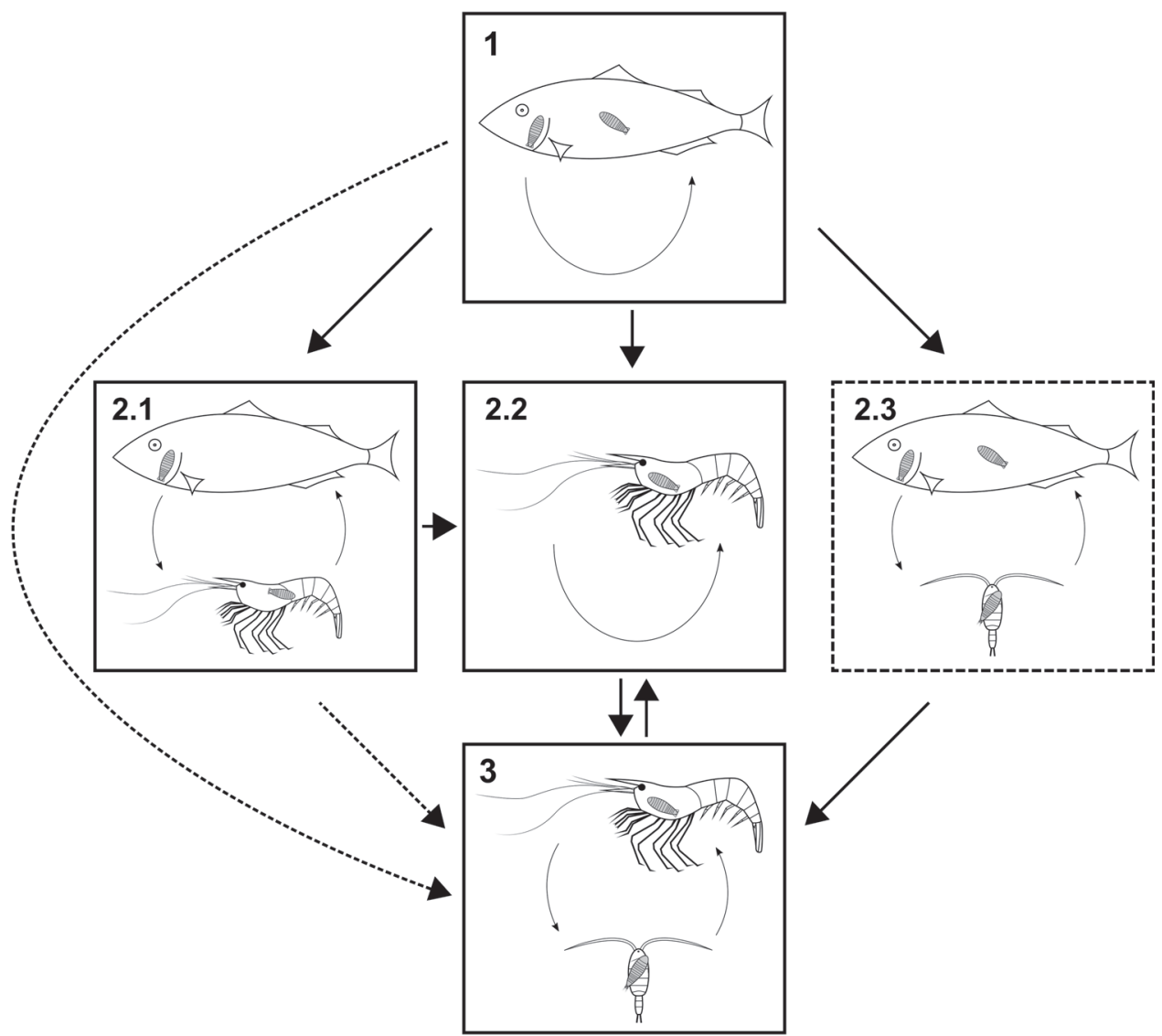

FIGURE 18. Possible evolutionary transitions between parasitic lifestyles in isopods (Cymothoida). Solid boxes, lifestyles with modern analogue; dashed box, lifestyle without modern analogue; solid arrows, likely transitions; dashed arrows, possible but less likely transitions. 18.1: Strict fish parasites, larvae or larvae and adults are parasiting fish (Aegidae, Cymothoidae, Gnathiidae). 18.2.1: Mixed fish and crustacean parasites, adult females parasitic to fish (some cymothoids). 18.2.2: Crustacean parasites without copepod intermediate host (Entoniscoides okadai, Epicaridea). 18.2.3: Larvae feed on copepods, adult females feed on fish. 18.3: Larvae feed on copepods and adults are parasitic to other crustaceans.

common ancestor of cymothoids and epicarideans. Likewise, protandric sexual development (Brusca, 1981) could be an ancestral for both groups (Dreyer and Wägele, 2001). A transition from a fish to a crustacean host is not difficult to imagine. Males of Cymothoidae (Thelota henseli) have even been reported feeding on palaemonid shrimps (De Castro, 1985). The involvement of a smaller crustacean (copepod) as intermediate host complicates the evolutionary scenario of the epicaridean life cycle. Indeed, aside of a single species (Entoniscoides okadai Miyashita, 1940) that seems to lack the epicaridium stage (Miyashita, 1940), all epicaridean species feed on copepods as intermediate host (Wägele, 1989). This suggests that copepods have already been involved as hosts in the life cycle of the common ancestor of all modern species. This leaves several equivalently parsimonious scenarios for the host change (Figure 18). It is possible that the life cycle of epicarideans evolved directly from a fish parasitic ancestor (Figure 18.1-18.3). This would have required the following significant evolutionary steps: (1) change in final host and adaption of cryptoniscium/adult for attachment onto decapods, (2) adaption to crustacean diet and (3) development of a specialised larva that, during this stage, attaches to a single copepod. However, some of these features could already have been present in the common ancestor of Epicaridea/Cymothoidae/Aegidae (Figure 18.2.1, 18.2.2, 18.2.3). Indeed, some representatives of Cymothoidae actually display an intermediate stage on a crustacean host (Thelota henseli De Castro, 1985) before colonizing their fish final host (Figure 18.2.1).

The lack of epicaridium larvae in one species of Epicaridea (Entoniscoides okadai, Miyashita, 1940) suggests that this species does not feed on 
copepods but exclusively on the final host, a crustacean. A condition as in Entoniscoides okadai (Figure 18.2.2) could have evolved directly from fish parasitism (Figure18.1) or from mixed fishcrustacean parasitism (Figure 18.2.1). It is possible that the modern epicaridean life cycle evolved from a condition like in Entoniscoides okadai by adding an intermediate smaller crustacean host. However, there is no support for Entoniscoides okadai to represent an early branch within Epicaridea. Therefore, it is likely that this life cycle evolved from the regular epicaridean life cycle (Figure 18.3 to 18.2.2). Likewise, also a transitory lifestyle involving fished as final hosts and copepods as intermediate hosts (Figure 18.2.3) could be considered. Yet, this scenario lacks a known extant analogue.

In this regard, we stress out that epicarideans are not restricted to crustacean as hosts. Pascual et al. (2002), indeed, revealed in a spectacular way the presence of endoparasitic cryptonisciumshaped life stages of epicarideans in squids. The authors of this report also emphasized that this may have been overseen for a long time due to the small size of the isopod parasites.

\section{Preservational Biases}

Scanning electron microscopy showed that the surface of cryptoniscium larvae (and males) is covered by fine grooves and fringes (e.g., Hosie, 2008). Due to the small scale of most of the surface structures, most of these surface structures could likely not be properly visualized in amber by light microscopy. Yet, some of the (larger scaled) surface structures, like the dorsal striation pattern, are visible in a few specimens. We explain this by two reasons. Some specimens are closer to the amber surface than others. The specimens located deeper in the amber are more difficult to photograph and also organic particles, cracks and cloudy areas of the resin can interfere with the microscopic results and therefore prevent surface structures to be observed. Yet, in some cases different surface structures are apparent in the same specimen (not affected by the location in amber, e.g., Figure 8.7). A cracked-open specimen (Figure 6.6) shows that (at least in some specimens) the exoskeleton is preserved in Vendean amber. Judging also from a specimen that shows a transition between a smooth and crater-like dorsal surface (Figure 8.3), we assume that these differences in the surface texture are caused by taphonomy rather than by differences in the original texture of the living animal.

\section{Taphonomic Environment}

Apart from the material studied herein, which was briefly mentioned and partially figured in Néraudeau et al. (2017), there is only one other record of epicaridean body fossils. SerranoSánchez et al. (2016) reported seven specimens (most likely cryptoniscia) from Miocene Chiapas amber (Mexico). All specimens come from the amber site Campo La Granja which is dissimilar to other Chiapas amber sites with respect to its high proportion of aquatic arthropod species and the stratified build-up of the resin (Serrano-Sánchez et al., 2015). The stratified build-up of the resin can also be seen in Vendean amber (Figure 4.3). However, in Campo La Granja amber the layers of resin are often intersected with grains of sand (SerranoSánchez et al., 2015), which has not been observed in Vendean amber. For Vendean amber Néraudeau et al. (2017) mentioned two categories of resin pieces: "stalactite-like" and "flat and multilayered." Yet, all fossil epicarideans from Vendée were found in the flat and multilayered amber pieces. This raises the question whether the buildup of the resin is actually linked to a taphonomic environment.

How aquatic and especially brackish/marine organisms could have been trapped in amber has long been debated. Two main processes have been discussed. The organisms could have been transported to the resin producers by wind, spray or tides (Girard et al., 2008; Schmidt et al., 2018) or they could have lived in proximity to the resin producers (Serrano-Sánchez et al., 2015).

Schmidt and Dilcher (2007) supported the possibility of the latter process by observations in a modern swamp environment and showed that this kind of entrapment is not only possible, but also likely to happen when the resin producer is located in an environment with stagnant water, where at least few extant epicaridean species live (Chopra, 1923).

Resin is not soluble in water and has a hydrophobic surface that prevents the volatiles to leave the resin. Thus, the resin stays in a liquid condition for a longer period of time and can function as a submerged trap for living organisms (until water levels drop and the resin hardens). Dead material can also be overflown and subsequently embedded in resin (Schmidt and Dilcher, 2007). The authors observed that living animals can promote getting fully immersed in the resin by autonomous motion.

In Campo La Granja amber, taphonomic circumstances strongly point out that at least some 
aquatic arthropod individuals must have been alive when trapped in the resin. This is dramatically shown by traces of torn off arthropod appendages leading to the corresponding bodies that lack exactly those appendages (Serrano-Sánchez et al., 2015). Although there is no such strong evidence for the entrapment of living aquatic arthropods in Vendean amber, a living condition still is the best scenario that explains the number and density of aquatic epicaridean larvae.

In this aspect, not only their large number of specimens in the French amber is informative, but also the fact that the French and the Mexican amber each include pieces that contain two specimens. This is quite remarkable and suggests a high density of larvae in the environment or a great chance for them to get stuck in the resin.

Even though the majority of extant epicaridean species is found in marine and brackish environments, there are also records of epicarideans living in true freshwater environments (Chopra, 1923). Thus, the herein described fossils alone cannot be used as an indicator for marine influence. However, many other findings such as plant pollen (Nohra et al., 2015), diatoms (Néraudeau et al., 2017; Saint Martin et al., 2015), dinoflagellates (Legrand et al., 2006), foraminifers (Legrand et al., 2006) and tanaidaceans (Sánchez-García et al., 2016) suggest a temporarily flooded near-shore palaeoenvironment that is comparable to extant cypress swamps.

The reconstructed coastal environment could have provided host species suitable for epicaridean larvae (crustaceans). However, only one crustacean species (Tanaidacea) has been recorded for Vendean amber (Sánchez-García et al., 2016; Néraudeau et al., 2017). Yet, no parasite-host relationship between epicarideans and tanaidaceans has ever been recorded, and the tanaidaceans known from Vendean amber are too small to represent final hosts of epicarideans (Eurotanais seilacheri in Sánchez-García et al., 2016).

\section{TAXONOMIC ACT}

EUARTHROPODA (sensu Walossek, 1999)

EUCRUSTACEA (sensu Walossek, 1999)

PERACARIDA Calman, 1904

ISOPODA Latreille, 1817

SCUTOCOXIFERA Dreyer et Wägele, 2002 CYMOTHOIDA Wägele, 1989

EPICARIDEA Latreille, 1825 (=Bopyridae

Rafinesque, 1815 sensu Wägele, 1989) VACUOTHECA gen. nov.
Type species. Vacuotheca dupeorum sp. nov. (type and only species).

Etymology. From the Latin words vacuus and theca, meaning empty case.

Remarks. The species cannot be interpreted with certainty as a representative of any already known epicaridean ingroup. Hence, it is required by the International Code of Zoological Nomenclature (ICZN, Chapter 2, Article 5 and App. B, 6.) to erect a new genus name. No diagnosis can be given for Vacuotheca gen. nov. as it includes only the type species (monospecific), and it cannot be differentiated which characters should diagnose the higher taxonomic unit. A possible alternative has been suggested by Lanham (1965). After Lanham, the uniqueness of a species name can be given by the species name along with detailed bibliographic information on the original description (uninomial nomenclature).

\section{Vacuotheca dupeorum sp. nov.}

Figures 5-15

zoobank.org/64997B3E-E77A-4095-A72C-726DC7710D39

v.2017 Epicaridean larva (depicted is the paratype IGR.GAR-8.1-2); Ne raudeau, Perrichot, Batten, Boura, Girard, Jeanneau, Nohra, Polette, S. Saint Martin, J. Saint Martin, Thomas, fig. 9A.

v.2014 Isopoda indet.; Perrichot and Néraudeau, tab. A1.

Etymology. From the last name of Fanny and André Dupé, who found and donated the amber specimens.

Holotype. IGR.GAR-28.

Paratypes. IGR.GAR-8.1-1, IGR.GAR-8.1-2, IGR.GAR-8.2, IGR.GAR-41-1, IGR.GAR-41-2, IGR.GAR-48, IGR.GAR-51, IGR.GAR-53-1, IGR.GAR-53-2, IGR.GAR-64, IGR.GAR-65, IGR.GAR-89, IGR.GAR-90, IGR.GAR-92, IGR.GAR-93, IGR.GAR-94, IGR.GAR-95-1, IGR.GAR-95-2, IGR.GAR-97, IGR.GAR-98. All deposited in the Geological Department and Museum of the University Rennes 1.

Ontogenetic stage of the types. Cryptoniscium larva or adult male (see discussion below).

Type locality. La Robinière (municipal of La Garnache, department of Vendée, France).

Type stratum. Unknown; Turonian age (Late Cretaceous) after Néraudeau et al. (2017).

Differential diagnosis. The cryptoniscium larva of Vacuotheca dupeorum sp. nov. differs from that of all (but one) known and sufficiently illustrated species in having an antennular plate (proximal element of the antennula) with 8 posteriorly directed teeth, the second antennular element having no 
teeth-like projections, the antenna having 5 flagellum elements, the coxal plates having 4 posterior teeth on each segment, the endopod of the uropod being longer than the exopod and the telson having 6 posterior teeth. For the remaining species Cironiscus dahli Nielsen and Strömberg, 1967, V. dupeorum sp. nov. differs in the shape of the antennular plate (first element) and the size of the third antennular element. The unnamed fossil Miocene cryptoniscium larvae reported in SerranoSánchez et al. (2016) show too few details to morphologically differentiate all of the Mexican specimens from the Vacuotheca dupeorum sp. nov. type specimens. Only the slightly larger size of the Miocene fossils could be used as a morphological distinction.

Also, it remains the possibility that there is an extant epicaridean species that does not differ in the larval morphology from $V$. dupeorum sp. nov. in the above listed characters but could not be located in the literature by the authors of this study. However, the large time span of 90 million years between the occurrence of $V$. dupeorum sp. nov. (Cretaceous) to extant species, respectively 67 million years between the occurrence of $V$. dupeorum sp. nov. and the Miocene Mexican fossils makes it highly unlikely that they belong to an extant species in the sense of the biological or phylogenetic species concept.

Remark on the Citation of Dajidae. The group of Dajidae was not established by Giard and Bonnier (1887) as stated by many authors in the recent literature (e.g., Boyko et al., 2013 'WORMS') but by Sars (1883). Thus, the correct citation is: Dajidae Sars, 1883.

\section{CONCLUSIONS}

The studied fossils represent cryptoniscium larvae or paedomorphic males of a highly specialised group of parasitic isopod species (Epicaridea) that feed on crustaceans. Fossils of epicarideans are extremely rare and, so far, only known from one other location, extending the fossil record of
Epicaridea by 67 million years. The fossils are very small but exceptionally well preserved. It was possible to date back many morphological features seen in extant cryptoniscium larvae to a Cretaceous age. All specimens appear to be conspecific and Vacuotheca dupeorum sp. nov. is described as a new species different from all known fossil and extant species in the morphology of the cryptoniscium larva. Extant epicaridean species have a much wider range in body size for the cryptoniscium stage larvae than the $V$. dupeorum sp. nov. type specimens. The evolution of the epicaridean life cycle as it is observed in the extant representatives is still enigmatic. Yet, some likely transitional conditions have been observed in extant representatives (although these conditions are likely not plesiomorphic). The herein presented specimens make a valid point for the hypothesis that at least some aquatic animals that are preserved in amber are indeed the result of entrapment that happened underwater.

\section{ACKNOWLEDGEMENTS}

We are grateful to all amateur palaeontologists who had been involved in the discovery, excavation and the preparation of the Vendean amber fossils. We warmly appreciate the effort of the contributors to the free and open source software, which was used during the preparation of this manuscript. We thank A.A. Klompmaker, N. Robin and M. Hyžný (handling editor) for their valuable comments, which helped to improve the quality of the manuscript. We thank C. Haug and J.M.Starck (both Munich) for their long-standing support. The project was kindly funded by the Deutsche Forschungsgemeinschaft (DFG Ha 6300/3-2). J. Haug is kindly funded by the Volkswagen Foundation (Lichtenberg professorship). Studies on the geology and paleodiversity of Vendean amber were partly supported by a CNRS-INSU grant through project Interrvie NOVAMBRE 2 (to $D$. Néraudeau and V. Perrichot, University of Rennes 1).

\section{REFERENCES}

Adkinson, D.L. and Collard, S.B. 1990. Description of the cryptoniscium larva of Entophilus omnitectus Richardson, 1903 (Crustacea: Isopoda: Epicaridea) and records from the Gulf of Mexico. Proceedings of the Biological Society of Washington, 103:649-654. 
Adlard, R.D. and Lester, R.J.G. 1995. The life-cycle and biology of Anilocra pomacentri (Isopoda, Cymothoidae), an ectoparasitic isopod of the coral-reef fish, Chromis nitida (Perciformes, Pomacentridae). Australian Journal of Zoology, 43:271-281.

Anderson, G. 1975. Larval metabolism of the epicaridian isopod parasite Probopyrus pandalicola and metabolic effects of $P$. pandalicola on its copepod intermediate host Acartia tonsa. Comparative Biochemistry and Physiology Part A: Physiology, 50:747-751. https://doi.org/ 10.1016/0300-9629(75)90140-1

Anderson, G. and Dale, W.E. 1981. Probopyrus pandalicola (Packard) (Isopoda, Epicaridea): morphology and development of larvae in culture. Crustaceana, 41:143-161. https://doi.org/ $10.1163 / 156854081 \times 00192$

An, J., Boyko, C.B., and Li, X. 2015. A review of bopyrids (Crustacea: Isopoda: Bopyridae) parasitic on caridean shrimps (Crustacea: Decapoda: Caridea) from China. Bulletin of the American Museum of Natural History, 399:1-85. https://doi.org/10.1206/amnb-921-00-01.1

Atkins, D. 1933. Pinnotherion vermiforme Giard and Bonnier, an entoniscid infecting Pinnotheres pisum. Proceedings of the Zoological Society of London, 103:319-363. https://doi.org/ 10.1111/j.1096-3642.1933.tb01598.x

Ax, P. 2000. The Phylogenetic System of the Metazoa. Multicellular Animals. Springer-Verlag, Berlin.

Bell, T. 1863. A Monograph of the fossil Malacostracous Crustacea of Great Britain, Part II, Crustacea of the Gault and Greensand. Palaeontographical Society Monograph I, II, Palaeontographical Society, London.

Béthoux, O. 2010. Optimality of phylogenetic nomenclatural procedures. Organisms Diversity \& Evolution, 10:173-191. https://doi.org/10.1007/s13127-010-0005-3

Blaxter, J.H., Douglas, B., Tyler, P.A., and Mauchline, J. 1998. The Biology of Calanoid Copepods 33. Academic Press, San Diego.

Bonnier, J. 1900. Contribution à l'étude des épicarides les Bopyridae. Travaux de la Station Zoologique de Wimereux, Paris.

Bourdon, R. 1968. Les Bopyridae des mers européennes. Mémoires du Muséum National d'Histoire naturelle (A), 50:77-424.

Bourdon, R. 1972. Epicarides de la Galathea Expedition. Galathea Report, 12:101-112.

Bourdon, R. 1976. Épicarides de Madagascar. I. Bulletin du Muséum National d'Histoire Naturelle, 3:353-392.

Bourdon, R. 1981. Trois nouveaux Cryptoniscina antarctiques abyssaux (Isopoda, Epicaridea). Bulletin du Muséum National d'Histoire Naturelle, 3:603-613.

Bourdon, R. and Bruce, N.L. 1980. Ancyroniscus orientalis sp. nov. (Isopoda: Epicaridea), nouveau cabiropside parasite de la « great barrier reef ». Bulletin de l'Academie et de la Societe Lorraines des Sciences, 19:21-26.

Boyko, C. 2015. A Revision of Danalia Giard, 1887, Faba Nierstrasz \& Brender à Brandis, 1930 and Zeuxokoma Grygier, 1993 (Crustacea: Isopoda: Epicaridea: Cryptoniscoidea: Cryptoniscidae) with description of a new genus and four new species. Bishop Museum Bulletin in Zoology, 9:65-92.

Boyko, C., Bruce, N.L., Hadfield, K.A., Merrin, K.L., Ota, Y., Poore, G.C.B., Taiti, S., Schotte, M., and Wilson, G.D.F. (eds.). 2008. World Register of Marine Species. Retrieved August 7, 2018.

Boyko, C.B., Moss, J., Williams, J.D., and Shields, J.D. 2013. A molecular phylogeny of Bopyroidea and Cryptoniscoidea (Crustacea: Isopoda). Systematics and Biodiversity, 11:495-506. https://doi.org/10.1080/14772000.2013.865679

Boyko, C.B., Schotte, M., Boyko, C.B., Bruce, N.L., Merrin, K.L., Ota, Y., Poore, G.C.B., Taiti, S., Schotte, M., and Wilson, G.D.F. 2013. Dajidae Giard \& Bonnier, 1887. World Marine, Freshwater and Terrestrial Isopod Crustaceans Database. Accessed through: World Register of Marine Species at http://www.marinespecies.org/aphia.php.

Boyko, C. and Williams, J. 2009. Crustacean parasites as phylogenetic indicators in decapod evolution, p. 197-220. In Martin, J., Crandall, K., and Felder, D. (eds.), Decapod Crustacean Phylogenetics. CRC Press, Boca Raton.

Boyko, C.B. and Williams, J.D. 2015. A new genus for Entophilus mirabiledictu Markham \& Dworschak, 2005 (Crustacea: Isopoda: Cryptoniscoidea: Entophilidae) with remarks on morphological support for epicaridean superfamilies based on larval characters. Systematic Parasitology, 92:13-21. https://doi.org/10.1007/s11230-015-9578-8 
Boyko, C.B. and Wolff, C. 2014. Isopoda and Tanaidacea, p. 210-212. In Martin, J.W., Olesen, J., and Hoeg, J.T. (eds.), Atlas of Crustacean Larvae. Johns Hopkins University Press, Baltimore.

Brandt, A. and Poore, G.C. 2003. Higher classification of the flabelliferan and related Isopoda based on a reappraisal of relationships. Invertebrate Systematics, 17:893-923. https:// doi.org/10.1071/IS02032

Bresciani, J. 1966. Aegophila socialis gen. et sp. nov., an epicaridean parasitic on the isopod Aega ventrosa Sars. Ophelia, 3:99-112. https://doi.org/10.1080/00785326.1966.10409636

Bruce, N.L. 2009. The marine fauna of New Zealand: Isopoda, Aegidae (Crustacea). Biodiversity Memoir. National Institute of Water and Atmospheric Research, Wellington.

Brusca, R.C. 1978. Studies on the cymothoid fish symbionts of the eastern Pacific (Isopoda, Cymothoidae) I. Biology of Nerocila californica. Crustaceana 34:141-154.

Brusca, R.C. 1981. A monograph on the Isopoda Cymothoidae (Crustacea) of the eastern Pacific. Zoological Journal of the Linnean Society, 73:117-199. https://doi.org/10.1111/j.10963642.1981.tb01592.x

Brusca, R.C. and Wilson, G.D.F. 1991. A phylogenetic analysis of the Isopoda with some classificatory recommendations. Memoirs of the Queensland Museum, 31:143-204.

Calman, W.T. 1904. XVIII. On the classification of the Crustacea Malacostraca. Annals and Magazine of Natural History, 13:144-158. https://doi.org/10.1080/00222930408562451

Caroli, E. 1928. La fase "micronisci" di lone thoracica (Montagu) ottenuta per allevamento sui copepodi. Accademia Nazionale dei Lincei Rendiconti, 6:321-326.

Caullery, M. 1907. Recherches sur les Liriopsidae, Épicarides cryptonisciens parasites des Rhizocéphales. Mittheilungren aus der Zoologischen Station zu Neapel, 18:583-643.

Chopra, B. 1923. Bopyrid isopods parasitic on Indian Decapoda Macrura. Records of the Indian Museum, 25:411-550.

Cohen, K.M., Finney, S.C., Gibbard, P.L., and Fan, J.-X. 2013, updated. The ICS International Chronostratigraphic Chart. Episodes, 36:199-204.

Coleman, C. 2003. Digital inking: how to make perfect line drawings on computers. Organisms Diversity \& Evolution, 3:303-304. https://doi.org/10.1078/1439-6092-00081

Coyle, K.O. and Mueller, G.J. 1981. Larval and juvenile stages of the isopod Holophryxus alaskensis (Epicarida, Dajidae) parasitic on decapods. Canadian Journal of Fisheries and Aquatic Sciences, 38:1438-1443. https://doi.org/10.1139/f81-190.

Dale, W.E. and Anderson, G. 1982. Comparison of morphologies of Probopyrus bithynis, $P$. floridensis, and $P$. pandalicola larvae reared in culture (Isopoda, Epicaridea). Journal of Crustacean Biology, 2:392-409. https://doi.org/10.2307/1548055

De Castro, A.L. 1985. Ectoparasitism of Telotha henselii (Von Martens) (Isopoda, Cymothoidae) on Macrobrachium brasiliense (Heller) (Decapoda, Palaemonidae). Crustaceana, 49:200201. https://doi.org/10.1163/156854085X00440

de Queiroz, K. and Gauthier, J. 1990. Phylogeny as a central principle in taxonomy: phylogenetic definitions of taxon names. Systematic Zoology, 39:307. https://doi.org/10.2307/2992353

de Queiroz, K. and Gauthier, J. 1994. Toward a phylogenetic system of biological nomenclature. Trends in Ecology \& Evolution, 9:27-31. https://doi.org/10.1016/0169-5347(94)90231-3

Dreyer, H. and Wägele, J.-W. 2001. Parasites of crustaceans (Isopoda: Bopyridae) evolved from fish parasites: molecular and morphological evidence. Zoology, 103:157-178.

Dreyer, H. and Wägele, J.-W. 2002. The Scutocoxifera tax. nov. and the information content of nuclear ssu rDNA sequences for reconstruction of isopod phylogeny (Peracarida: Isopoda). Journal of Crustacean Biology, 22:217-234. https://doi.org/10.1163/20021975-99990229

Fraisse, P. 1878. Die Gattung Cryptoniscus Fr. Müller. Arbeiten aus dem ZoologischZootomischen Institut in Würzburg, 4:239-296.

Giard, A. and Bonnier, J.J. 1887. Contributions à l'étude des Bopyriens. Travaux de la Station Zoologique de Wimereux, 5. Imprimerie L. Danel, Lille.

Girard, V., Schmidt, A.R., Martin, S.S., Struwe, S., Perrichot, V., Martin, J.-P.S., Grosheny, D., Breton, G., and Néraudeau, D. 2008. Evidence for marine microfossils from amber. Proceedings of the National Academy of Sciences, 105:17426-17429. https://doi.org/ 10.1073/pnas.0804980105

Goudeau, M. 1969. Appareil buccal et mécanisme alimentaire chez l'Isopode Epicaride Hemioniscus balani Buchholz. Archives de Zoologie Expérimentale et Générale, 110:473512. 
Goudeau, M. 1977. Contribution à la biologie d'un crustacé parasite: Hemioniscus balani Buchholz, isopode épicaride. Nutrition, mues et croissance de la femelle et des Embryons. Cahiers de Biologie Marine, 18:201-242.

Haug, J.T., in press. Why the term "larva" is ambiguous, or what makes a larva? Acta Zoologica, 1-22. https://doi.org/10.1111/azo.12283

Haug, J.T. and Haug, C. 2016. "Intermetamorphic" developmental stages in 150 million-year-old achelatan lobsters - the case of the species tenera Oppel, 1862. Arthropod Structure \& Development, 45:108-121. https://doi.org/10.1016/j.asd.2015.10.001

Haug, J.T., Maas, A., Haug, C., and Waloszek, D. 2013. Evolution of crustacean appendages, p. 34-73. In Watling, L. and Thiel, M. (eds.), Functional Morphology and Diversity. Oxford University Press, Oxford. https://doi.org/10.1093/acprof:osobl/9780195398038.003.0002

Hiraiwa, Y.K. 1936. Studies on a bopyrid, Epipenaeon japonica Thielemann. III. Development and life-cycle, with special reference to the sex differentiation in the bopyrid. Journal of Science of the Hiroshima University (Zoology), 4:101-141.

Holdich, D.M. 1975. Ancyroniscus bonnieri (Isopoda, Epicaridea) infecting British populations of Dynamene bidentata (Isopoda, Sphaeromatidae). Crustaceana, 28:145-151. https://doi.org/ 10.1163/156854075X00694

Hosie, A.M. 2008. Four new species and a new record of Cryptoniscoidea (Crustacea: Isopoda: Hemioniscidae and Crinoniscidae) parasitising stalked barnacles from New Zealand. Zootaxa, 1795:1-28. https://doi.org/10.11646/zootaxa.1795.1.1

International Commission on Zoological Nomenclature. 2012. Retrieved June 8, 2018, from http:/ /www.nhm.ac.uk/hosted-sites/iczn/code/.

Kensley, B. 1979. Redescription of Zonophryxus trilobus Richardson, with notes on the male and developmental stages (Crustacea: Isopoda: Dajidae). Proceedings of the Biological Society of Washington, 92:665-670.

Keyser, D. and Weitschat, W. 2005. First record of ostracods (Crustacea) in Baltic amber. Hydrobiologia, 538:107-114. https://doi.org/10.1007/s10750-004-5941-5

Klompmaker, A.A., Artal, P., Van Bakel, B.W.M., Fraaije, R.H.B., and Jagt, J.W.M. 2014. Parasites in the fossil record: a Cretaceous fauna with isopod-infested decapod crustaceans, infestation patterns through time, and a new ichnotaxon. PLoS One, 9:e92551. https:// doi.org/10.1371/journal.pone.0092551

Klompmaker, A.A. and Boxshall, G.A. 2015. Fossil crustaceans as parasites and hosts. Advances in Parasitology, 90:233-289. https://doi.org/10.1016/bs.apar.2015.06.001

Klompmaker, A.A., Portell, R.W., and Frick, M.G. 2017. Comparative experimental taphonomy of eight marine arthropods indicates distinct differences in preservation potential. Palaeontology, 60:773-794. https://doi.org/10.1111/pala.12314

Lang, C., Krapp, T., and Melzer, R.R. 2007. Postembryonal development in Caprellidae: SEM description and comparison of ready-to-hatch juveniles and adults of two Mediterranean skeleton shrimps (Crustacea: Amphipoda). Zootaxa, 1605:1-32. https://doi.org/10.11646/ zootaxa.1605.1.1

Lanham, U. 1965. Uninominal nomenclature. Systematic Zoology, 14:144-144.

Latreille, P.A. 1817. Le règne animal distribué d'après son organisation: pour servir de base a l'histoire naturelle des animaux et d'introduction a l'anatomie comparée. Chez Déterville, Paris.

Latreille, P.A. 1825. Familles naturelles du règne animal, exposées succinctement et dans un ordre analytique, avec lindication de leurs genres. J. B. Baillière, Paris. https://doi.org/ 10.5962/bhl.title.16094

Legrand, J., Viaud, J.M., Pouit, D., and Pons, D. 2006. Upper Cretaceous woody structures and associated microfloral data from western France. 7th European Paleobotany-Palynology Conference, Prague, p. 80.

Markham, J.C. 1986. Evolution and zoogeography of the Isopoda Bopyridae, parasites of Crustacea Decapoda, p. 143-164. In Gore, R.H. and Heck, K.L. (eds.), Crustacean Issues 4. Crustacean Biogeography. A.A. Balkema, Rotterdam.

Marshall, S.M. and Orr, A.P. 1972. The Biology of a Marine Copepod: Calanus finmarchicus (gunnerus). Oliver \& Boyd, Edinburgh.

Mayr, E. 1940. Speciation phenomena in birds. The American Naturalist, 74:249-278.

Mayr, E. 1942. Systematics and the Origin of Species, from the Viewpoint of a Zoologist. Columbia University Press, New York. 
McDermott, J.J. 2002. Relationships between the parasitic isopods Stegias clibanarii Richardson, 1904 and Bopyrissa wolffi Markham, 1978 (Bopyridae) and the intertidal hermit crab Clibanarius tricolor (Gibbes, 1850) (Anomura) in Bermuda. Ophelia, 56:33-42. https:// doi.org/10.1080/00785236.2002.10409487

Miyashita. 1940. On an entoniscid with abbreviated development, Entoniscoides okadai, n. g., n. sp. Annotationes Zoologicae Japonenses, 19:149-157.

Müller, F. 1862. Entoniscus porcellanae, eine neue Schmarotzerassel. Archiv für Naturgeschichte, 28(1):10-18.

Nagler, C. and Haug, J.T. 2015. From fossil parasitoids to vectors. Advances in Parasitology, 90:137-200. https://doi.org/10.1016/bs.apar.2015.09.003

Nagler, C., Hyžný, M., and Haug, J.T. 2017. 168 million years old "marine lice" and the evolution of parasitism within isopods. BMC Evolutionary Biology, 17:76. https://doi.org/10.1186/ s12862-017-0915-1

Néraudeau, D., Perrichot, V., Batten, D.J., Boura, A., Girard, V., Jeanneau, L., Nohra, Y.A., Polette, F., Saint Martin, S., and Saint Martin, J.-P. 2017. Upper Cretaceous amber from Vendée, north-western France: age dating and geological, chemical, and palaeontological characteristics. Cretaceous Research, 70:77-95. https://doi.org/10.1016/ j.cretres.2016.10.001

Nielsen, S.-O. 1967. Cironiscus dahli gen. et sp. nov. (Crustacea, Epicaridea) with notes on hostparasite relations and distribution. Sarsia, 29:395-412. https://doi.org/10.1080/ 00364827.1967 .10411096

Nielsen, S.-O. and Strömberg, J.-O. 1965. A new parasite of Cirolana borealis Lilljeborg belonging to the Cryptoniscinae (Crustacea Epicaridea). Sarsia, 18:37-62. https://doi.org/ 10.1080/00364827.1965.10409547

Nielsen, S.-O. and Strömberg, J.-O. 1973. Morphological characters of taxonomical importance in Cryptoniscina (Isopoda Epicaridea) A scanning electron microscopic study of cryptoniscus larvae. Sarsia, 52:75-96.

Nohra, Y., Perrichot, V., Jeanneau, L., and Azar, D. 2015. Chemical characterization and botanical origin of French ambers. Journal of Natural Products, 78:1284-1293. https://doi.org/ 10.1021/acs.jnatprod.5b00093

Ogg, J.G., Hinnov, L.A., and Huang, C. 2012. The Geologic Time Scale. Elsevier. https://doi.org/ 10.1016/B978-0-444-59425-9.00027-5

Oliveira, E. and Masunari, S. 2006. Distribuição temporal de densidade de Aporobopyrus curtatus (Richardson) (Crustacea, Isopoda, Bopyridae), um parasito de Petrolisthes armatus (Gibbes) (Crustacea, Anomura, Porcellanidae) na Ilha do Farol, Matinhos, Paraná, Brasil. Revista Brasileira de Zoologia, 23:1188-1195. https://doi.org/10.1590/S010181752006000400028

Owens, L. and Rothlisberg, P.C. 1991. Vertical migration and advection of bopyrid isopod cryptoniscid larvae in the Gulf of Carpentaria, Australia. Journal of Plankton Research, 13:779-787. https://doi.org/10.1093/plankt/13.4.779

Pascual, S., Vega, M.A., José Rocha, F., and Guerra, A. 2002. First report of an endoparasitic epicaridean isopod infecting cephalopods. Journal of Wildlife Diseases, 38:473-477. https:// doi.org/10.7589/0090-3558-38.2.473

Penalver, E. and Delclòs, X. 2010. Spanish amber, p. 236-270. In Penney, D. (ed.), Biodiversity of Fossils in Amber from the Major World Deposits. Siri Scientific Press, Manchester.

Perrichot, V. and Néraudeau, D. 2014. Introduction to thematic volume "Fossil arthropods in Late Cretaceous Vendean amber (northwestern France)". Paleontological Contributions, 10A:1-4. https://doi.org/10.17161/PC.1808.15981

Perrichot, V., Néraudeau, D., and Tafforeau, P. 2010. Charentese amber, p. 192-207. In Penney, D. (ed.), Biodiversity of Fossils in Amber from the Major World Deposits. Siri Scientific Press, Manchester.

Rafinesque, C.S. 1815. Analyse de la nature ou tableau de l'univers et des corps organisés. Jean Barravecchia, Palermo.

Revell, L.J. 2017. Phytools: Phylogenetic Tools for Comparative Biology (and Other Things). Retrieved April 25, 2018, from https://CRAN.R-project.org/package=phytools.

Reverberi, G. 1947. Ancora sulla trasformazione sperimentale del sesso nei Bopiridi. La trasformazione della femmine giovanili in maschi. Pubblicazioni della Stazione Zoologica di Napoli, 21:83-93. 
Román-Contreras, R. and Romero-Rodríguez, J. 2013. Prevalence and reproduction of Bopyrina abbreviata (Isopoda, Bopyridae) in Laguna de Términos, SW Gulf of Mexico. Journal of Crustacean Biology, 33:641-650. https://doi.org/10.1163/1937240X-00002182

Romero-Rodríguez, J. and Román-Contreras, R. 2008. Aspects of the reproduction of Bopyrinella thorii (Richardson, 1904) (Isopoda, Bopyridae), a branchial parasite of Thor floridanus Kingsley, 1878 (Decapoda, Hippolytidae) in Bahía de la Ascensión, Mexican Caribbean. Crustaceana, 81:1201-1210. https://doi.org/10.1163/156854008X374522

Rybakov, A.V. 1990. Bourdonia tridentata gen. n., sp. n. (Isopoda: Cabiropsidae) a hyperparasite of Bopyroides hippolytes Kroyer from the shrimp Pandalus borealis. Parazitologiia, 24:408416.

Saint Martin, S., Saint Martin, J.-P., Schmidt, A.R., Girard, V., Néraudeau, D., and Perrichot, V. 2015. The intriguing marine diatom genus Corethron in Late Cretaceous amber from Vendée (France). Cretaceous Research, 52:64-72. https://doi.org/10.1016/j.cretres.2014.07.006

Sánchez-García, A., Peñalver, E., Bird, G.J., Perrichot, V., and Delclòs, X. 2016. Palaeobiology of tanaidaceans (Crustacea: Peracarida) from Cretaceous ambers: extending the scarce fossil record of a diverse peracarid group. Zoological Journal of the Linnean Society, 178:492-522. https://doi.org/10.1111/zoj.12427

Sars, G.O. 1883. Oversigt af Norges Crustaceer med foreloebige Bemaerkninger over de nye eller mindrebekjendte Arter. Videnskabs-Selskabet i Christiana, 18:68-75.

Schmidt, A.R. and Dilcher, D.L. 2007. Aquatic organisms as amber inclusions and examples from a modern swamp forest. Proceedings of the National Academy of Sciences, 104:1658116585. https://doi.org/10.1073/pnas.0707949104

Schmidt, A.R., Grabow, D., Beimforde, C., Perrichot, V., Rikkinen, J., Saint Martin, S., Thiel, V., and Seyfullah, L.J. 2018. Marine microorganisms as amber inclusions: insights from coastal forests of New Caledonia. Fossil Record, 21:213-221. https://doi.org/10.5194/fr-21-213-2018

Schmidt, A.R., Schönborn, W., and Schäfer, U. 2004. Diverse fossil amoebae in German Mesozoic amber. Palaeontology, 47:185-197. https://doi.org/10.1111/j.00310239.2004.00368.x

Schultz, G.A. 1975. Bathypelagic isopod Crustacea from the Antarctic and southern seas, p. 69128. In Schultz, G.A. (ed.), Biology of the Antarctic Seas V. American Geophysical Union, Richmond, Virginia.

Schultz, G.A. 1980. Arcturocheres gaussicola n. sp. (Cabiropsidae) parasite on Antarcturus gaussianus Vanhöffen (Arcturidae) from Antarctica (Isopoda). Crustaceana, 39:153-156. https://doi.org/10.1163/156854080X00058

Serrano-Sánchez, M. de L., Hegna, T.A., Schaaf, P., Pérez, L., Centeno-García, E., and Vega, F.J. 2015. The aquatic and semiaquatic biota in Miocene amber from the Campo La Granja mine (Chiapas, Mexico): paleoenvironmental implications. Journal of South American Earth Sciences, 62:243-256. https://doi.org/10.1016/j.jsames.2015.06.007

Serrano-Sánchez, M. de L., Nagler, C., Haug, C., Haug, J.T., Centeno-García, E., and Vega, F.J. 2016. The first fossil record of larval stages of parasitic isopods: cryptoniscus larvae preserved in Miocene amber. Neues Jahrbuch für Geologie und PaläontologieAbhandlungen, 279:97-106. https://doi.org/10.1127/njgpa/2016/0543

Shields, J.D. and Ward, L.A. 1998. Tiarinion texopallium, new species, an entoniscid isopod infesting majid crabs (Tiarinia spp.) from the Great Barrier Reef, Australia. Journal of Crustacean Biology, 18:590-596. https://doi.org/10.1163/193724098X00412

Shimomura, M., Ohtsuka, S., and Naito, K. 2005. Prodajus curviabdominalis n. sp. (Isopoda: Epicaridea: Dajidae), an ectoparasite of mysids, with notes on morphological changes, behaviour and life-cycle. Systematic Parasitology, 60:39-57. https://doi.org/10.1007/s11230004-1375-8

Shino, S.M. 1965. Phylogeny of the genera within the family Bopyridae. Bulletin du Museum National d'Histoire Naturelle, Series 2, 37:462-465.

Strömberg, J.-O. 1971. Contribution to the embryology of bopyrid isopods with special reference to Bopyroides, Hemiarthrus, and Peseudione (Isopoda, Epicaridea). Sarsia 47:1-46. https:// doi.org/10.1080/00364827.1971.10411191

Strömberg, J.-O. 1983. A redescription of Onisocryptus sagittus Schultz 1977 (Epicaridea, Cryptoniscina) with notes on hosts, distribution and family relationships. Polar Biology, 2:8794. https://doi.org/10.1007/BF00303173 
Thamban, A.P., Kappalli, S., Kottarathil, H.A., Gopinathan, A., and Paul, T.J. 2015. Cymothoa frontalis, a cymothoid isopod parasitizing the belonid fish Strongylura strongylura from the Malabar Coast (Kerala, India): redescription, description, prevalence and life cycle. Zoological Studies 54:42. https://doi.org/10.1186/s40555-015-0118-7

Thompson, M.T. 1901. A new isopod parasitic on the hermit crab. Bulletin of the U.S. Fisheries Commission, 21:53-56.

Torres Jordá, M. 2003. Estudio de la Relación Entre el Parásito Leidya Distorta (Isopoda: Bopyridae) y su Hospedador Uca uruguayensis (Brachyura: Ocypodidae), y Descripción de los Estadíos Larvales de L. Distorta. Doctoral thesis, Universidad de Buenos Aires, Buenos Aires.

Truesdale, F.M. and Mermilliod, W.J. 1977. Some observations on the host-parasite relationship of Macrobrachium ohione (Smith) (Decapoda, Palaemonidae) and Probopyrus bithynis Richardson (Isopoda, Bopyridae). Crustaceana, 32:216-220.

Tsukamoto, R.Y. 1981. Bopyrina ocellata (Czerniavsky, 1868), isópode parasita assinalada pela primeira vez no Atlântico Sul (Epicaridea, Bopyridae). Morfologia, desenvolvimento e distribuição geográfica. Ciência e Cultura, 33:394-401.

Uye, S. and Murase, A. 1997. Infertility of the planktonic copepod Calanus sinicus caused by parasitism by a larval epicaridian isopod. Plankton Biology \& Ecology, 44:97-99.

van der Wal, S., Smit, N.J., and Hadfield, K.A. 2019. Review of the fish parasitic genus Elthusa Schioedte \& Meinert, 1884 (Crustacea, Isopoda, Cymothoidae) from South Africa, including the description of three new species. ZooKeys, 841:1-37. https://doi.org/10.3897/ zookeys.841.32364

von Soergel, W. 1913. Lias und Dogger von Jefbei und Fialpopo (Misólarchipel), p. 586-650. In Boehm G. (ed.), Geologische Mitteilungen aus dem Indo-Australischen Archipel. Neues Jahrbuch für Mineralogie. E. Schweizerbartsche Verlagsbuchhandlung, Stuttgart.

Wägele, J.-W. 1989. Evolution und phylogenetisches System der Isopoda: Stand der Forschung und neue Erkenntnisse. Zoologica. Schweizerbart, Stuttgart.

Walossek, D. and Müller, K.J. 1998. Cambrian 'Orsten'-type arthropods and the phylogeny of Crustacea, p. 139-153. In Fortey, R.A. and Thomas, R.H. (eds.), Arthropod Relationships. The Systematics Association Special Volume Series. Springer Netherlands, Dordrecht. https://doi.org/10.1007/978-94-011-4904-4_12

Walossek, D. 1999. On the Cambrian diversity of Crustacea. Crustaceans and the Biodiversity Crisis. Proceedings of the Fourth International Crustacean Congress, Brill, Leiden, p. 3-27.

Wienberg Rasmussen, H., Jakobsen, S.L., and Collins, J.S.H. 2008. Raninidae infested by parasitic Isopoda (Epicaridea). Bulletin of the Mizunami Fossil Museum, 34:31-49.

Williams, J.D. and An, J. 2009. The cryptogenic parasitic isopod Orthione griffenis Markham, 2004 from the eastern and western Pacific. Integrative and Comparative Biology, 49:114-126. https://doi.org/10.1093/icb/icp021

Williams, J.D. and Boyko, C.B. 2012. The global diversity of parasitic isopods associated with crustacean hosts (Isopoda: Bopyroidea and Cryptoniscoidea). PLoS One, 7:e35350. https:// doi.org/10.1371/journal.pone.0035350

Williams, E.H. and Bunkley-Williams, L. 2019. Life cycle and life history strategies of parasitic Crustacea, p. 179-266. In Smit, N.J., Bruce, N.L., and Hadfield, K.A. (eds.), Parasitic Crustacea. State of Knowledge and Future Trends. Zoological Monographs 3. Springer International Publishing, Cham. https://doi.org/10.1007/978-3-030-17385-2_5

Wilson, G.D. 2009. The phylogenetic position of the Isopoda in the Peracarida (Crustacea: Malacostraca). Arthropod Systematics \& Phylogeny, 67:159-198.

Xing, L., Sames, B., McKellar, R.C., Xi, D., Bai, M., and Wan, X. 2018. A gigantic marine ostracod (Crustacea: Myodocopa) trapped in mid-Cretaceous Burmese amber. Scientific Reports, 8:1365. https://doi.org/10.1038/s41598-018-19877-y 


\section{APPENDIX 1.}

Preservation of the type specimens.

IGR.GAR-8.1: two specimens.

IGR.GAR-8.1-1: lateral view from the right body side; good visibility restricted to some areas; posterior pereopods (thoracic appendages), distal part of the antenna and uropods visible.

IGR.GAR-8.1-2: ventro-lateral view from the right body side; is depicted in Néraudeau (2017); covered with a layer of glue.

IGR.GAR-8.2: one specimen; visible from both lateral views; good visibility from the right body side and minor visibility from the left body side; antenna, dorsal striation pattern and coxal plates visible.

IGR.GAR-28 (holotype): one specimen; visible from two directions, ventrolateral view from the left body side and latero-dorsal view from the right body side; very good visibility; antennular plates, second and third antennula elements, antenna, oral cone, pereopods (thoracic appendages), coxal plates, pleopods and uropods visible.

IGR.GAR-41: two specimens.

IGR.GAR-41-1: dorsal view; good visibility only in the posterior region; dorsal shape of the head shield, dorsal outline, telson and uropods visible.

IGR.GAR-41-2: dorsal view, bad visibility except for the uropod region; uropods partly broken off, showing cross-sections of endo- and exopods.

IGR.GAR-48: one specimen; visible from two directions, latero-dorsal view from the left body side and ventro-lateral view from the right body side; relatively good visibility from both sides; dorsal surface including striation pattern, antennular plates, coxal plates, posterior pereopods (thoracic appendages) and first pleopods visible.

IGR.GAR-51: one specimen, ventral view; inclusion is cracked open and the interior surface of the cavity is visible, large parts of the right body side missing; dorsal striation pattern and telson ornamentation visible.

IGR.GAR-53: two specimens.

IGR.GAR-53-1: ventral view; very good visibility except for the uropods; antennulae, antennae, mouthparts, pereopods (thoracic appendages) and anterior pleopods visible.

IGR.GAR-53-2: visible from dorsal and ventral view; good visibility from dorsal view and bad visibility from ventral view; antennae, dorsal striation pattern, telson and uropods visible.

IGR.GAR-64: one specimen; latero-ventral view from the left body side; bad visibility; antennular plates, rough shapes of pereopods (thoracic appendages) and pleopods and uropods visible.

IGR.GAR-65: one specimen; postero-lateral view from the left body side; relatively good visibility; body on the left side partially abraded (grinded off during preparation); posterior pereopods (thoracic appendages) and pleopods visible.

IGR.GAR-89: one specimen; antero-ventral view; partially good visibility; antenna, pereopods (thoracic appendages), pleopod setation and uropods visible.

IGR.GAR-90: one specimen; ventral view; inclusion is at the surface of the amber and cracked open showing the interior surface of the cavity and features of the head morphology.

IGR.GAR-92: one specimen; lateral view from the left body side; good visibility restricted to some areas; dorsal surface including striation pattern visible.

IGR.GAR-93: one specimen; visible from two directions, latero-dorsal view from the left body side and latero-ventral view from the right body side; good visibility with exception for the pleo- 
pod region; dorsal surface including striation pattern, antennular plate, antenna, oral cone, coxal plates and posterior pereopods (thoracic appendages) visible.

IGR.GAR-94: one specimen; lateral view from the right body side; good visibility, antenna, posterior pereopods (thoracic appendages) and uropods visible.

IGR.GAR-95: two specimens.

IGR.GAR-95-1: ventral view, good visibility restricted to some areas; antennula, antenna, pereopods (thoracic appendages), coxal plates and uropods visible.

IGR.GAR-95-2: lateral view from the right body side; bad visibility; only rough shape visible.

IGR.GAR-97: one specimen; ventral view; good visibility except for uropods; antennulae, pereopods (thoracic appendages) and pleopods visible.

IGR.GAR-98: one specimen; dorsal view; partially good visibility; antennae, dorsal striation pattern and uropods visible. 


\section{APPENDIX 2.}

Character states of five selected characters in cryptoniscium larvae from the literature (data used in Figure 16) (available as zipped file at https://palaeo-electronica.org/content/2019/2757-cretaceous-epicaridea).

\section{APPENDIX 3.}

Body lengths of different life stages of epicarideans, aegids and cymothoids from the literature and from the herein studied specimens (data used in Figure 17) (available as zipped file at https:/ /palaeo-electronica.org/content/2019/2757-cretaceous-epicaridea).

\section{APPENDIX 4.}

Stack of single fluorescence microscopy images of the head region of specimen IGR.GAR-28 (cf. Figure 10.2 and Figure 12.7) (available as zipped file at https://palaeo-electronica.org/content/2019/2757-cretaceous-epicaridea).

\section{APPENDIX 5.}

Stack of single fluorescence microscopy images of the head region of specimen IGR.GAR-53-1 (cf. Figure 10.2 and Figure 12.4) (available as zipped file at https://palaeo-electronica.org/content/2019/2757-cretaceous-epicaridea). 